\title{
Supply Shocks, Demand Shocks, and Labor Market Fluctuations
}

\author{
Helge Braun, Reinout De Bock, and Riccardo DiCecio
}

\begin{abstract}
The authors use structural vector autoregressions to analyze the responses of worker flows, job flows, vacancies, and hours to demand and supply shocks. They identify these shocks by restricting the short-run responses of output and the price level. On the demand side, they disentangle a monetary and nonmonetary shock by restricting the response of the interest rate. The responses of labor market variables are similar across shocks: Expansionary shocks increase job creation, the job-finding rate, vacancies, and hours; and they decrease job destruction and the separation rate. Supply shocks have more persistent effects than demand shocks. Demand and supply shocks are equally important in driving business cycle fluctuations of labor market variables. The authors' findings for demand shocks are robust to alternative identification schemes involving the response of labor productivity at different horizons. Supply shocks identified by restricting productivity generate a higher fraction of impulse responses inconsistent with standard search and matching models. (JEL C32, E24, E32, J63)
\end{abstract}

Federal Reserve Bank of St. Louis Review, May/June 2009, 91(3), pp. 155-78.

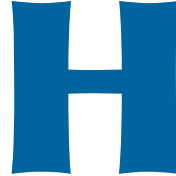

all (2005) and Shimer (2004) argue that the search and matching model of Mortensen and Pissarides (1994) is unable to reproduce the volatility of the job-finding rate, unemployment, and vacancies observed in the data. ${ }^{1}$ A growing literature has attempted to amend the basic MortensenPissarides model to match these business cycle facts. ${ }^{2}$ Although most of this literature considers shocks to labor productivity as the source of fluctuations, some authors invoke the responses

\footnotetext{
1 Also see Andolfatto (1996).

2 See, for example, Hagedorn and Manovskii (2008) and Mortensen and Nagypál (2005).
}

to other shocks as a potential resolution (see Silva and Toledo, 2005). These analyses are based on the assumption that either the unconditional moments are driven to a large extent by a particular shock or the responses of the labor market to different shocks are similar. This article takes a step back and asks, What are the contributions of different aggregate shocks to labor market fluctuations and how different are the labor market responses to various shocks? The labor market variables we analyze are worker flows, job flows, vacancies, and hours. Including both worker flows and job flows allows us to analyze the different conclusions authors have reached on the importance of the hiring versus the separa-

Helge Braun is a lecturer of economics at Universität zu Köln, Reinout De Bock is an economist at the International Monetary Fund, and Riccardo DiCecio is an economist at the Federal Reserve Bank of St. Louis. The authors thank Paul Beaudry, Larry Christiano, Luca Dedola, Martin Eichenbaum, Natalia Kolesnikova, Daniel Levy, Dale Mortensen, Éva Nagypál, Frank Smets, Murat Tasci, Yi Wen, and seminar participants at the European Central Bank, Ghent University, 2006 Midwest Macroeconomics Meetings, WEAI 81st Annual Conference, University of British Columbia, and the Board of Governors for helpful comments, as well as Steven Davis and Robert Shimer for sharing their data. Helge Braun and Reinout De Bock thank the Research Division at the Federal Reserve Bank of St. Louis and the European Central Bank, respectively, for their hospitality. Charles Gascon provided research assistance.

(C) 2009, The Federal Reserve Bank of St. Louis. The views expressed in this article are those of the author(s) and do not necessarily reflect the views of the Federal Reserve System, the Board of Governors, the regional Federal Reserve Banks, or the International Monetary Fund. Articles may be reprinted, reproduced, published, distributed, displayed, and transmitted in their entirety if copyright notice, author name(s), and full citation are included. Abstracts, synopses, and other derivative works may be made only with prior written permission of the Federal Reserve Bank of St. Louis. 
tion margin in driving changes in employment and unemployment. Including aggregate hours relates our work to the literature on the response of hours to technology shocks.

We identify three aggregate shocks—supply shocks, monetary shocks, and nonmonetary demand shocks-using a structural vector autoregression (structural VAR, or SVAR). Restrictions are placed on the signs of the dynamic responses of aggregate variables as in Uhlig (2005) and Peersman (2005). The first identification scheme we consider places restrictions on the short-run responses of output, the price level, and the interest rate. Supply shocks move output and the price level in opposite directions, while demand shocks generate price and output responses of the same sign. Additionally, monetary shocks lower the interest rate on impact; other demand shocks do not. These restrictions can be motivated by a basic IS-LM-AD-AS framework or by New Keynesian models. The responses of job flows, worker flows, hours, and vacancies are left unrestricted.

The main results for the labor market variables are as follows: The responses of hours, job flows, worker flows, and vacancies are qualitatively similar across shocks. A positive demand or supply shock increases vacancies and the job-finding and job-creation rates, and it decreases the separation and job-destruction rates. As in Fujita (2004), the responses of vacancies and the job-finding rate are persistent and hump shaped. Furthermore, the responses induced by demand shocks are less persistent than those induced by supply shocks. For all shocks, changes in the job-finding rate are responsible for the bulk of changes in unemployment, although separations contribute up to one half of the change on impact. Changes in employment, on the other hand, are mostly driven by the job-destruction rate. As in Davis and Haltiwanger (1999), we find that job reallocation falls after expansionary shocks, especially demand-side shocks. We find no evidence of differences in the matching process of unemployed workers and vacancies in response to different shocks. Finally, each of the demand-side shocks is at least as important as the supply-side shock in explaining fluctuations in labor market variables.

There is mild evidence in support of a technological interpretation of the supply shocks identified by restricting output and the price level. The response of labor productivity is positive for supply shocks at medium-term horizons, whereas it is insignificantly different from zero for demand shocks. To check the robustness of our results, we modify the identification scheme by restricting the medium-run response of labor productivity to identify the supply-side shock, while leaving the short-run responses of output and the price level unrestricted. This is akin to a long-run restriction on the response of labor productivity used in the literature (see Galì, 1999). Consistent with the first identification scheme, technology shocks tend to raise output and decrease the price level in the short run. Labor market responses to supply shocks under this identification scheme are less apparent. In particular, the responses of vacancies, worker flows, and job flows to supply shocks are not significantly different from zero. Again, the demand-side shocks are at least as important in explaining fluctuations in the labor market variables as the supply shock.

We also identify a technology shock, using a long-run restriction on labor productivity, and a monetary shock, by means of the recursiveness assumption used by Christiano, Eichenbaum, and Evans (1999). Again, we find that the responses to the technology shock are not significantly different from zero. The responses to the monetary shock are consistent with the ones identified above. The contribution of the monetary shock to the variance of labor market variables exceeds that of the technology shock.

We also analyze the subsample stability of our results. We find a reduction in the volatility of shocks for the post-1984 subsample, consistent with the Great Moderation literature. The main conclusions from the analysis above apply to both subsamples.

Finally, we use a small VAR that includes only non-labor market variables and hours to identify the shocks. We then uncover the responses of the labor market variables by regressing them on distributed lags of the shocks. ${ }^{3}$ Our findings are robust to this alternative empirical strategy.

\footnotetext{
3 This procedure is used by Beaudry and Portier (2004) to analyze the effects of news shocks identified in a small VAR including only an index of stock market value and total factor productivity on other variables of interests, such as consumption and investment.
} 
Our results suggest that a reconciliation of the Mortensen-Pissarides model should equally apply to the response of labor market variables to demand-side shocks. Furthermore, the response to supply-side shocks is much less clear cut than implicitly assumed in the bulk of the literature. In a related paper (Braun, De Bock, and DiCecio, 2006) we further explore the labor market responses to differentiated supply shocks (see also López-Salido and Michelacci, 2007).

Our findings suggest that the "hours debate" spawned by Galì (1999) is relevant for business cycle models with a frictional labor market à la Mortensen-Pissarides. In trying to uncover the source of business cycle fluctuations, several authors have argued that a negative response of hours worked to supply shocks is inconsistent with the standard real business cycle (RBC) model. These results are often interpreted as suggesting that demand-side shocks must play an important role in driving the cycle and are used as empirical support for models that depart from the RBC standard by incorporating nominal rigidities and other frictions. We provide empirical evidence on the response of job flows, worker flows, and vacancies. This is a necessary step to evaluate the empirical soundness of business cycle models with a labor market structure richer than the competitive structure typical of the RBC models or the stylized sticky wages structure often adopted in New Keynesian models. The importance of demand shocks in driving labor market variables and the atypical responses to supply shocks can be interpreted as a milder version of the "negative response of hours" findings.

In the next sections, we describe the data used in the analysis and the identification procedure and then discuss our results. The final section contains the robustness analysis.

\section{WORKER FLOWS AND JOB FLOWS DATA}

Worker flows are measured by the separation and job-finding rates constructed by Shimer (2007). Their construction is summarized in the next subsection. The following subsections discuss job flows-which are measured by the jobcreation and job-destruction series constructed by Faberman (2004) and Davis, Faberman, and Haltiwanger (2006) —and the business cycle statistics of the data.

\section{Separation and Job-Finding Rates}

The separation rate measures the rate at which workers leave employment and enter the unemployment pool. The job-finding rate measures the rate at which unemployed workers exit the unemployment pool. Although the rates are constructed and interpreted while omitting flows between labor market participation and nonparticipation, Shimer (2007) shows that they capture most of the behavior of both the unemployment and employment pools over the business cycle. The advantage of using these data lies in their availability for a long time span. The data constructed by Shimer are available from 1947, whereas worker flow data including nonparticipation flows from the Current Population Survey (CPS) are available only from 1967 onward.

The separation and job-finding rates are constructed using data on the short-term unemployment rate as a measure of separations and the law of motion for the unemployment rate to back out a measure of the job-finding rate. The size of the unemployment pool is observed at discrete dates $t, t+1, t+2$, etc. Hirings and separations occur continuously between these dates. To identify the relevant rates within a time period, assume that between dates $t$ and $t+1$, separations and job finding occur with constant Poisson arrival rates $s_{t}$ and $f_{t}$, respectively. For some $\tau \in(0,1)$, the law of motion for the unemployment pool $U_{t+\tau}$ is

$$
\dot{U}_{t+\tau}=E_{t+\tau} s_{t}-U_{t+\tau} f_{t},
$$

where $E_{t+\tau}$ is the pool of employed workers and $E_{t+\tau} s_{t}$ are the inflows and $U_{t+\tau} f_{t}$ the outflows from the unemployment pool at $t+\tau$. The analogous expression for the pool of short-term unemployed $U_{t+\tau}^{S}$ (i.e., those workers who have entered the unemployment pool after date $t$ ) is:

$$
\dot{U}_{t+\tau}^{s}=E_{t+\tau} s_{t}-U_{t+\tau}^{s} f_{t} .
$$


Combining expressions (1) and (2) gives

$$
\dot{U}_{t+\tau}=\dot{U}_{t+\tau}^{s}-\left(U_{t+\tau}-U_{t+\tau}^{s}\right) f_{t} .
$$

Solving the differential equation using $U_{t}^{S}=0$ as the initial condition yields

$$
U_{t+1}=U_{t} e^{-f_{t}}+U_{t+1}^{s} .
$$

Given data on $U_{t}, U_{t+1}$, and $U_{t+1}^{S}$, the last expression is used to construct the job-finding rate, $f_{t}$. The separation rate then follows from

$$
U_{t+1}=\left(1-e^{-f_{t}-s_{t}}\right) \frac{s_{t}}{f_{t}+s_{t}} L_{t}+e^{-f_{t}-s_{t}} U_{t},
$$

where $L_{t} \equiv\left(U_{t}+E_{t}\right)$ is the labor force. Notice that the rates $s_{t}$ and $f_{t}$ are time-aggregation-adjusted versions of $U_{t+1}^{s} / E_{t+1}$ and $\left(U_{t}-U_{t+1}+U_{t+1}^{S}\right) / U_{t+1}$, respectively. The construction of $s_{t}$ and $f_{t}$ takes into account that workers may experience multiple transitions between dates $t$ and $t+1$. These rates are continuous-time arrival rates and the corresponding probabilities are $S_{t}=\left(1-e^{-S_{t}}\right)$ and $F_{t}=\left(1-e^{-f_{t}}\right)$, respectively.

Using equation (4), observe that if $\left(f_{t}+s_{t}\right)$ is large, the unemployment rate, $U_{t+1} / L_{t}$, can be approximated by the steady-state relationship $u_{t+1} \cong s_{t} /\left(s_{t}+f_{t}\right)$. As shown by Shimer (2007), this turns out to be an accurate approximation to the actual unemployment rate. We use this approximation to infer changes in unemployment from the responses of $f_{t}$ and $s_{t}$ in the SVAR. To gauge the relative importance of the job-finding and separation rates in determining unemployment, we follow Shimer (2007) and construct the following variables:

- $s_{t} /\left(s_{t}+f_{t}\right)$ is the approximated unemployment rate;

- $\bar{s}_{t} /\left(\bar{s}_{t}+f_{t}\right)$ is the hypothetical unemployment rate computed with the actual jobfinding rate, $f_{t}$, and the average separation rate, $\bar{s}$;

- $s_{t} /\left(s_{t}+\bar{f}\right)$ is the hypothetical unemployment rate computed with the average jobfinding rate, $\bar{f}$, and the actual separation rate, $s_{t}$.

Inflows into the employment pool are measured by the job-finding rate and not, as in Fujita
(2004), by the hiring rate. The hiring rate sums all worker flows into the employment pool and scales them by current employment. Its construction is analogous to the job-creation rate defined for job flows. The response of the hiring rate to shocks is in general not very persistent, as opposed to that of the job-finding rate. This difference is due to the scaling. We discuss this point in more detail below.

\section{Job Creation and Job Destruction}

The job flows literature focuses on job-creation (JC) and job-destruction (JD) rates. ${ }^{4}$ Gross job creation sums employment gains at all plants that expand or start up between $t-1$ and $t$. Gross job destruction, on the other hand, sums up employment losses at all plants that contract or shut down between $t-1$ and $t$. To obtain the creation and destruction rates, both measures are divided by the averages of employment at $t-1$ and $t$. Davis, Haltiwanger, and Schuh (1996) construct measures for both series from the Longitudinal Research Database (LRD) and the monthly Current Employment Statistics (CES) survey from the Bureau of Labor Statistics (BLS). ${ }^{5}$ A number of researchers work only with the quarterly job-creation and jobdestruction series from the LRD. ${ }^{6}$ Unfortunately, these series are available only for the 1972:Q11993:Q4 period.

This paper uses the quarterly job flows data constructed by Faberman (2004) and Davis, Faberman, and Haltiwanger (2006). These authors splice together data from (i) the Manufacturing Turnover Survey (MTD) from 1947 to 1982, (ii)

\footnotetext{
4 See Davis and Haltiwanger (1992), Davis, Haltiwanger, and Schuh (1996), Davis and Haltiwanger (1999), Caballero and Hammour (2005), and López-Salido and Michelacci (2007).

5 As pointed out in Blanchard and Diamond (1990) these job-creation and -destruction measures differ from true job creation and destruction as (i) they ignore gross job creation and destruction within firms, (ii) the point-in-time observations do not take into account job-creation and -destruction offsets within the quarter, and (iii) they fail to account for newly created jobs that are not yet filled with workers.

${ }^{6}$ Davis and Haltiwanger (1999) extend the series back to 1948. Some authors report that this extended series is (i) somewhat less accurate and (ii) tracks only aggregate employment in the 1972:Q1-1993:Q4 period (see Caballero and Hammour, 2005).
} 


\section{Figure 1}

\section{Worker and Job Flows: Levels and Business Cycle Components}
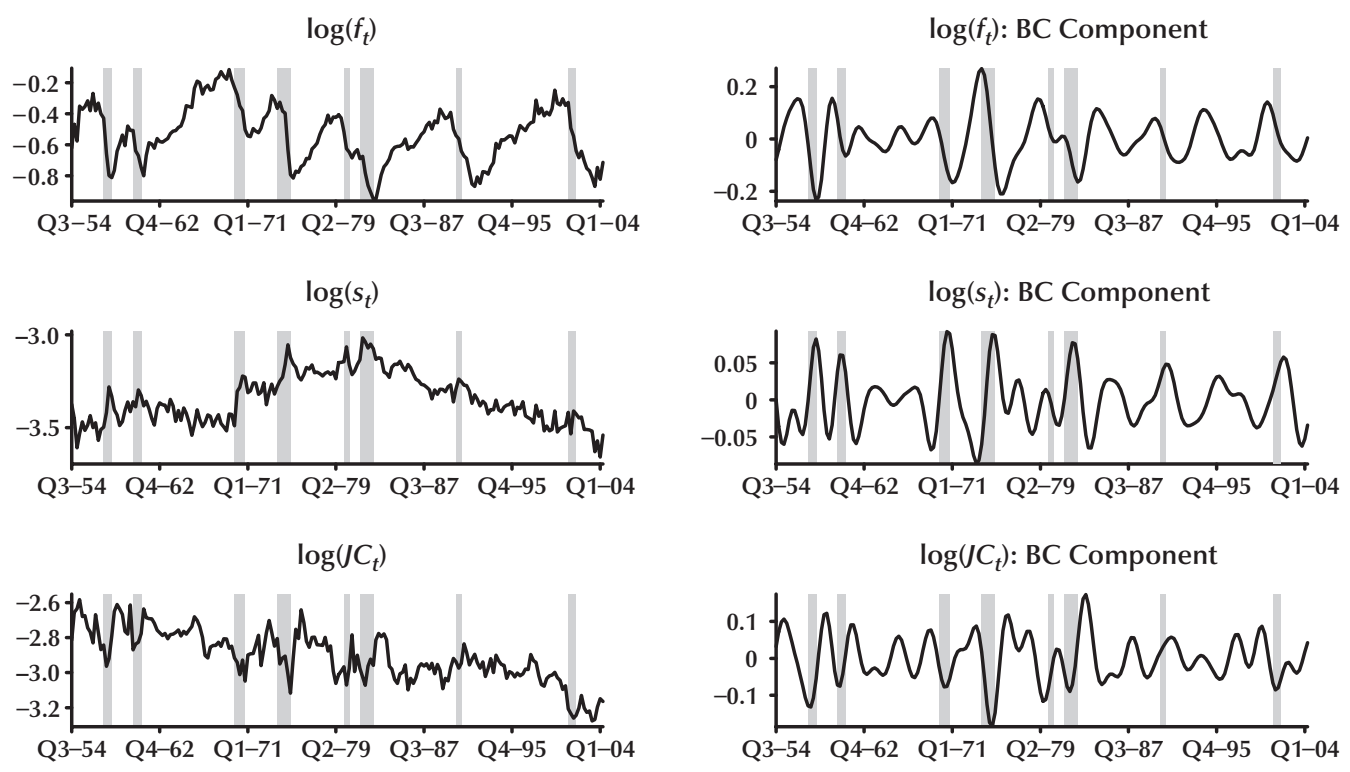

$\log \left(J C_{t}\right):$ BC Component

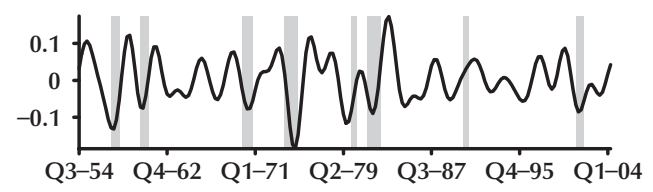

$\log \left(J D_{t}\right)$

$\log \left(J D_{t}\right):$ BC Component
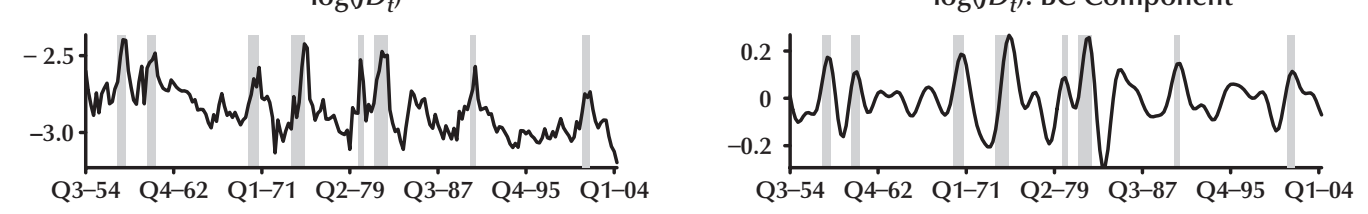

NOTE: The business cycle component is extracted with a $\mathrm{BP}(8,32)$ filter. Shaded areas denote the NBER recessions.

the LRD from 1972 to 1998, and (iii) the Business Employment Dynamics (BED) from 1990 to 2004. The MTD and LRD data are spliced as in Davis and Haltiwanger (1999), whereas the LRD and BED splice follows Faberman (2004).

A fundamental accounting identity relates the net employment change between any two points in time to the difference between job creation and destruction. We define $g_{E, t}^{J C, J D}$ as the growth rate of employment implied by job flows:

$$
g_{E, t}^{J C, J D} \equiv \frac{E_{t}-E_{t-1}}{\left(E_{t}+E_{t-1}\right) / 2}=J C_{t}-J D_{t} .
$$

The data spliced from the MTD and LRD of the job-creation and -destruction rates constructed by Davis, Faberman, and Haltiwanger (2006) per- tain to the manufacturing sector. However, over the period 1954:Q2-2004:Q2, the implied growth rate of employment from these job flows data, $g_{E, t}^{J C, J D}=\left(J C_{t}-J D_{t}\right)$, is highly correlated with the growth rate of total nonfarm payroll employment,

$$
g_{E, t} \equiv\left[\frac{E_{t}-E_{t-1}}{0.5\left(E_{t}+E_{t-1}\right)}\right]: \operatorname{Corr}\left(g_{E, t}^{J C, D}, g_{E, t}\right)=0.89 .^{7}
$$

As in Davis, Haltiwanger, and Schuh (1996), we also define gross job reallocation as $r_{t} \equiv$ $\left(J C_{t}+J D_{t}\right)$. Using this definition we examine the reallocation effects of different shocks in the SVARs. We also look at cumulative reallocation.

7 The correlation of $g_{E, t}^{J C, J D}$ with the growth rate of employment in manufacturing is 0.93 . 
Table 1

Correlation Matrix of Business Cycle Components

\begin{tabular}{|c|c|c|c|c|c|c|c|c|c|}
\hline & $f$ & $s$ & $J C$ & $J \boldsymbol{D}$ & $\boldsymbol{u}$ & $v$ & $\boldsymbol{h}$ & $A P L$ & $y$ \\
\hline$f$ & $\begin{array}{c}6.27 \\
{[5.54,6.99]}\end{array}$ & $\begin{array}{c}-0.48 \\
{[-0.63,-0.29]}\end{array}$ & $\begin{array}{c}-0.04 \\
{[-0.24,0.15]}\end{array}$ & $\begin{array}{c}-0.53 \\
{[-0.66,-0.39]}\end{array}$ & $\begin{array}{c}-0.98 \\
{[-0.99,-0.96]}\end{array}$ & $\begin{array}{c}0.95 \\
{[0.93,0.97]}\end{array}$ & $\begin{array}{c}0.96 \\
{[0.93,0.98]}\end{array}$ & $\begin{array}{c}0.20 \\
{[-0.03,0.4]}\end{array}$ & $\begin{array}{c}0.88 \\
{[0.81,0.92]}\end{array}$ \\
\hline$S$ & & $\begin{array}{c}2.55 \\
{[2.21,2.99]}\end{array}$ & $\begin{array}{c}-0.55 \\
{[-0.68,-0.37]}\end{array}$ & $\begin{array}{c}0.86 \\
{[0.78,0.91]}\end{array}$ & $\begin{array}{c}0.54 \\
{[0.39,0.66]}\end{array}$ & $\begin{array}{c}-0.62 \\
{[-0.73,-0.49]}\end{array}$ & $\begin{array}{c}-0.48 \\
{[-0.61,-0.33]}\end{array}$ & $\begin{array}{c}-0.63 \\
{[-0.77,-0.44]}\end{array}$ & $\begin{array}{c}-0.67 \\
{[-0.78,-0.53]}\end{array}$ \\
\hline$J C$ & & & $\begin{array}{c}4.26 \\
{[3.61,4.97]}\end{array}$ & $\begin{array}{c}-0.58 \\
{[-0.7,-0.41]}\end{array}$ & $\begin{array}{c}0.08 \\
{[-0.10,0.26]}\end{array}$ & $\begin{array}{c}0.04 \\
{[-0.17,0.24]}\end{array}$ & $\begin{array}{c}-0.11 \\
{[-0.3,0.09]}\end{array}$ & $\begin{array}{c}0.53 \\
{[0.33,0.68]}\end{array}$ & $\begin{array}{c}0.14 \\
{[-0.11,0.36]}\end{array}$ \\
\hline$J D$ & & & & $\begin{array}{c}6.73 \\
{[5.89,7.59]}\end{array}$ & $\begin{array}{c}0.53 \\
{[0.40,0.63]}\end{array}$ & $\begin{array}{c}-0.65 \\
{[-0.76,-0.53]}\end{array}$ & $\begin{array}{c}-0.53 \\
{[-0.66,-0.39]}\end{array}$ & $\begin{array}{c}-0.70 \\
{[-0.82,-0.54]}\end{array}$ & $\begin{array}{c}-0.72 \\
{[-0.84,-0.58]}\end{array}$ \\
\hline$u$ & & & & & $\begin{array}{c}7.27 \\
{[6.39,8.24]}\end{array}$ & $\begin{array}{c}-0.95 \\
{[-0.96,-0.93]}\end{array}$ & $\begin{array}{c}-0.95 \\
{[-0.97,-0.92]}\end{array}$ & $\begin{array}{c}-0.18 \\
{[-0.38,0.01]}\end{array}$ & $\begin{array}{c}-0.86 \\
{[-0.90,-0.81]}\end{array}$ \\
\hline$v$ & & & & & & $\begin{array}{c}8.84 \\
{[8.13,9.78]}\end{array}$ & $\begin{array}{c}0.95 \\
{[0.94,0.97]}\end{array}$ & $\begin{array}{c}0.34 \\
{[0.14,0.53]}\end{array}$ & $\begin{array}{c}0.94 \\
{[0.9,0.96]}\end{array}$ \\
\hline$h$ & & & & & & & $\begin{array}{c}1.10 \\
{[1.01,1.19]}\end{array}$ & $\begin{array}{c}0.17 \\
{[-0.06,0.38]}\end{array}$ & $\begin{array}{c}0.89 \\
{[0.84,0.93]}\end{array}$ \\
\hline$A P L$ & & & & & & & & $\begin{array}{c}0.65 \\
{[0.56,0.77]}\end{array}$ & $\begin{array}{c}0.58 \\
{[0.43,0.7]}\end{array}$ \\
\hline$y$ & & & & & & & & & $\begin{array}{c}1 \\
{[\mathrm{NA}]}\end{array}$ \\
\hline
\end{tabular}

NOTE: Standard deviations (relative to output) are shown on the diagonal. All series were logged and detrended using a BP $(8,32)$ filter. Block-bootstrapped confidence intervals in brackets.

\section{Business Cycle Properties}

Figure 1 shows the levels and business cycle components $^{8}$ of worker and job flows along with the National Bureau of Economic Research (NBER) recession dates. Table 1 reports correlations and standard deviations (relative to output) for the business cycle component of worker flows, job flows, the unemployment rate $(u)$, vacancies $(v)$, hours per capita $(h)$, average labor productivity $(A P L)$, and output $(y) .{ }^{9}$ The job-finding rate and vacancies are strongly procyclical, with correlations with output of 0.88 and 0.96 , respectively. Job creation is moderately procyclical (0.14). The separation (-0.67), job-destruction $(-0.72)$, and the unemployment $(-0.86)$ rates are countercyclical. The diagonal of Table 1 reports volatilities. The

\footnotetext{
8 We used the band-pass filter described in Christiano and Fitzgerald (2003) for frequencies between 8 and 32 quarters to extract the business cycle component of the data.

9 See the appendix for data sources.
}

job-destruction rate (6.73) is one and a half times more volatile than the job creation rate (4.26). The job-finding rate (6.27) is twice as volatile as the separation rate (2.55). Notice that the jobdestruction and separation rates are positively correlated (0.86), whereas the job-creation and jobfinding rates are orthogonal to each other $(-0.04)$.

Table 2 reports correlations of the three unemployment approximations described in the subsection "Separation and Job-Finding Rates" with actual unemployment, as well as the standard deviations of the three approximations (relative to actual unemployment). The steady-state approximation to unemployment, $s_{t} /\left(s_{t}+f_{t}\right)$, is very accurate and the job-finding rate plays a bigger role in determining unemployment. The contribution of the job-finding rate is even larger at cyclical frequencies. ${ }^{10}$

\footnotetext{
10 Shimer (2005) uses a Hodrick-Prescott filter with smoothing parameter $10^{5}$. His choice of an unusual filter to detrend the data further magnifies the contribution of the job-finding rate to unemployment with respect to the figures we report.
} 


\section{Table 2}

\section{Contribution of the Job-Finding and Separation Rates to Unemployment: Levels and Business Cycle Components}

\begin{tabular}{|c|c|c|c|c|c|c|}
\hline & \multicolumn{3}{|c|}{ Levels } & \multicolumn{3}{|c|}{ Business cycle component } \\
\hline & $s_{t} /\left(s_{t}+f_{t}\right)$ & $\bar{s} /\left(\bar{s}+f_{t}\right)$ & $s_{t} /\left(s_{t}+\bar{f}\right)$ & $s_{t} /\left(s_{t}+f_{t}\right)$ & $\bar{s} /\left(\bar{s}+f_{t}\right)$ & $s_{t} /\left(s_{t}+\bar{f}\right)$ \\
\hline $\operatorname{Corr}\left(x, u_{t+1}\right)$ & $\begin{array}{c}0.99 \\
{[0.99,1]}\end{array}$ & $\begin{array}{c}0.85 \\
{[0.76,0.92]}\end{array}$ & $\begin{array}{c}0.79 \\
{[0.64,0.87]}\end{array}$ & $\begin{array}{c}0.99 \\
{[0.99,1]}\end{array}$ & $\begin{array}{c}0.93 \\
{[0.90,0.95]}\end{array}$ & $\begin{array}{c}0.74 \\
{[0.62,0.82]}\end{array}$ \\
\hline $\operatorname{Std}(x) / \operatorname{Std}\left(u_{t+1}\right)$ & $\begin{array}{c}1.01 \\
{[1,1.03]}\end{array}$ & $\begin{array}{c}0.69 \\
{[0.6,0.82]}\end{array}$ & $\begin{array}{c}0.49 \\
{[0.42,0.58]}\end{array}$ & $\begin{array}{c}1.03 \\
{[1.01,1.05]}\end{array}$ & $\begin{array}{c}0.79 \\
{[0.73,0.86]}\end{array}$ & $\begin{array}{c}0.31 \\
{[0.28,0.36]}\end{array}$ \\
\hline
\end{tabular}

NOTE: The business cycle component is extracted with a $\mathrm{BP}(8,32)$ filter. Block-bootstrapped confidence intervals in brackets.

\section{SVAR ANALYSIS}

This section describes the reduced-form VAR specification and provides an outline of the Bayesian implementation of sign restrictions. The variables included in the SVAR analysis are the growth rate of average labor productivity $\left(\Delta \log \left(Y_{t} / H_{t}\right)\right)$, the inflation rate $\left(\Delta \log \left(p_{t}\right)\right)$, hours $\left(\Delta \log \left(H_{t}\right)\right)$, worker flows, job flows, a measure of vacancies $\left(\Delta \log \left(v_{t}\right)\right)$, and the federal funds rate $\left(\log \left(1+R_{t}\right)\right)$. Worker flows are the job-finding and separation rates constructed in Shimer (2007).

Job flows are the job-creation and job-destruction series from Faberman (2004) and Davis, Faberman, and Haltiwanger (2006). Sources for the other data are given in the appendix. The sample covers the period 1954:Q2-2004:Q2. To achieve stationarity, we linearly detrend the logarithms of the job flows variables. The estimated VAR coefficients corroborate the stationarity assumption.

Consider the following reduced-form VAR ${ }^{11}$ :

$$
Z_{t}=\mu+\sum_{j=1}^{p} B_{j} Z_{t-j}+u_{t}, E\left(u_{t} u_{t}^{\prime}\right)=V,
$$

where $Z_{t}$ is defined as

$$
Z_{t}=\left[\begin{array}{l}
\Delta \log \left(\frac{Y_{t}}{H_{t}}\right), \Delta \log \left(p_{t}\right), \log \left(H_{t}\right), \\
\log \left(f_{t}\right), \log \left(s_{t}\right), \log \left(J C_{t}\right), \\
\log \left(D_{t}\right), \log \left(v_{t}\right), \ln \left(1+R_{t}\right)
\end{array}\right]^{\prime}
$$

The reduced-form residuals $\left(u_{t}\right)$ are mapped into the structural shocks $\left(\varepsilon_{t}\right)$ by the structural matrix $\left(A_{0}\right)$ as follows: $\varepsilon_{t}=A_{0} u_{t}$. The structural shocks are orthogonal to each other, i.e., $E\left(\varepsilon_{t} \varepsilon_{t}{ }^{\prime}\right)=\mathrm{I}$.

We identify the structural shocks using prior information on the signs of the responses of certain variables. First, we use short-run output and price responses to distinguish between demand and supply shocks (see section "Price and Output Restrictions"). In the section "Robustness," alternatively supply-side technology shocks are identified by restricting the medium-run response of labor productivity. As an ulterior robustness check, we also combine long-run and short-run restrictions more commonly used in the literature.

\section{Implementing Sign Restrictions}

The identification schemes are implemented following a Bayesian procedure. We impose a Jeffreys (1961) prior on the reduced-form VAR parameters:

$$
p(B, V) \propto\|V\|^{-\frac{n+1}{2}},
$$

where $B=\left[\mu, B_{1}, \ldots, B_{p}\right]^{\prime}$ contains the reducedform VAR parameters and $n$ is the number of variables in the VAR. The posterior distribution of the reduced-form VAR parameters belongs to the inverse Wishart-Normal family:

$$
\begin{aligned}
& \left(V \mid Z_{t=1, \ldots, T}\right) \sim I W(T \hat{V}, T-k), \\
& \left(B \mid V, Z_{t=1, \ldots, T}\right) \sim N\left(\hat{B}, V\left(X^{\prime} X\right)^{-1}\right),
\end{aligned}
$$

${ }^{11}$ Based on information criteria, we estimate a reduced-form VAR including two lags, i.e., $p=2$. 


\section{Table 3}

\section{Sign Restrictions: Demand and Supply Shocks}

\begin{tabular}{lccc} 
& \multicolumn{2}{c}{ Demand shocks } & \\
\cline { 2 - 3 } Variable & Monetary & Other & Supply shocks \\
\hline Output & $\uparrow 1-4$ & $\uparrow 1-4$ & $\uparrow 1-4$ \\
Price level & $\uparrow 1-4$ & $\uparrow 1-4$ & $\downarrow 1-4$ \\
Interest rate & $\downarrow 1$ & $\uparrow 1$ & -
\end{tabular}

where $\hat{B}$ and $\hat{V}$ are the ordinary least squares estimates of $B$ and $V, T$, is the sample length, $k=(n p+1)$, and $X$ is defined as

$$
\begin{aligned}
X & =\left[x_{1}^{\prime}, \ldots, x_{T}^{\prime}\right]^{\prime}, \\
x_{t}^{\prime} & =\left[1, Z_{t-1}^{\prime}, \ldots, Z_{t-p}^{\prime}\right]^{\prime} .
\end{aligned}
$$

Consider a possible orthogonal decomposition of the covariance matrix, i.e., a matrix $C$ such that $V=C C^{\prime}$. Then $C Q$, where $Q$ is a rotation matrix, is also an admissible decomposition. The posterior distribution on the reduced-form VAR parameters, a uniform distribution over rotation matrices, and an indicator function equal to zero on the set of impulse response functions (IRFs) that violate the identification restrictions induce a posterior distribution over the IRFs that satisfy the sign restrictions.

The sign restrictions are implemented as follows:

1. For each draw from the inverse WishartNormal family for $(V, B)$, we take an orthogonal decomposition matrix, $C$, and draw one possible rotation, $Q .{ }^{12}$

2. We check the signs of the impulse responses for each structural shock. If we find a set of structural shocks that satisfies the restrictions, we keep the draw. Otherwise we discard it.

3. We continue until we have 1,000 draws from the posterior distribution of the IRFs that satisfy the identifying restrictions.

\footnotetext{
${ }^{12}$ We obtain $Q$ by generating a matrix $X$ with independent standard normal entries, taking the $Q R$ factorization of $X$, and normalizing so that the diagonal elements of $R$ are positive.
}

\section{PRICE AND OUTPUT RESTRICTIONS}

The basic IS-LM-AD-AS model can be used to motivate the following restrictions to distinguish demand and supply shocks. Demand shocks move the price level and output in the same direction in the short run. Supply shocks, on the other hand, move output and the price level in opposite directions. On the demand side, we further distinguish between monetary and nonmonetary shocks: Monetary shocks lower the interest rate on impact, whereas nonmonetary demand shocks do not. The interest rate responses are restricted to one quarter, and the output and price-level responses are restricted to four quarters. These restrictions are similar to the ones used by Peersman (2005). ${ }^{13}$ The identifying restrictions are summarized in Table 3.

Figures 2 and 3 report the median, 16th, and 84th percentiles of 1,000 draws from the posterior distribution of acceptable IRFs of nonlabor market variables, labor market variables, and other variables of interest. ${ }^{14}$ Recall that labor market variables are left unrestricted. The response of output is hump shaped across shocks and more persistent for supply shocks. The response of hours is positive for all shocks and the response of labor productivity is positive for supply shocks.

For the response of the labor market variables displayed in Figure 3, the following main observations emerge:

- Similarity Across Shocks. The responses of labor market variables are qualitatively similar across shocks. Supply shocks generate more persistent, although less pronounced, responses than demand shocks. Supply shocks induce a larger fraction of atypical responses of labor market variables, such as an increase in job destruction on impact.

- Worker Flows, Unemployment, and Vacancies. The job-finding rate and vacan-

\footnotetext{
13 Peersman (2005) additionally restricts the response of the interes rate for supply shocks and the response of the oil price to further disentangle supply shocks.

14 The acceptance rate is 66.6 percent.
} 


\section{Figure 2}

\section{Price Restriction: IRFs for Non-Labor Market Variables and Hours (percent): Demand and Supply Shocks}
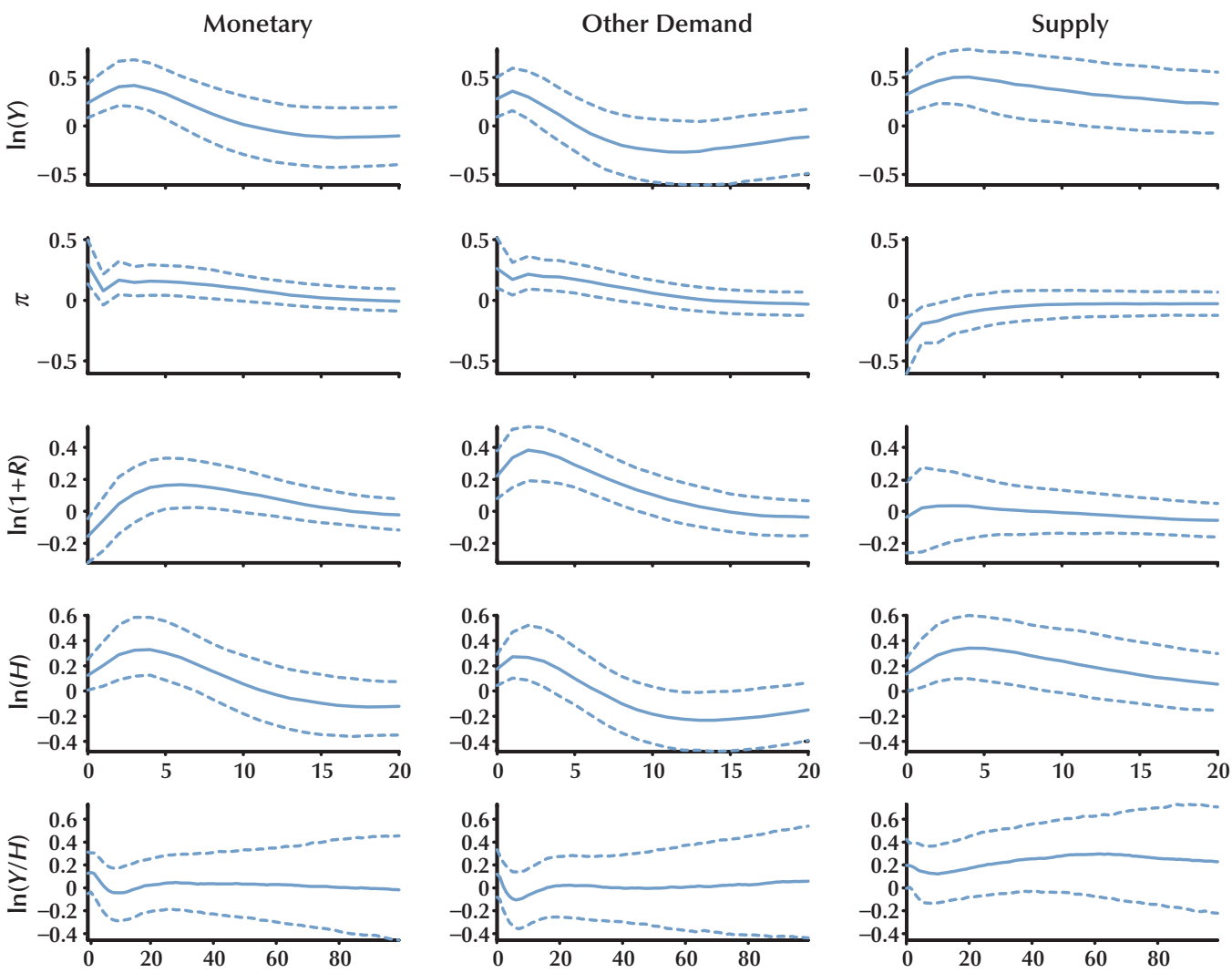

NOTE: Median (solid line), 16th and 84th percentiles (dashed lines) of posterior distributions.

cies respond in a persistent, hump-shaped manner. Separations are less persistent. In response to demand shocks, the unemployment rate decreases for 10 quarters and overshoots its steady-state value. In response to supply shocks, the unemployment rate decreases in a U-shaped way, displaying a more persistent response and no overshooting. The response of the unemployment rate to all shocks is mostly determined by the effect on the job-finding rate, as displayed by the black dashed line in the unemployment panel of Figure 3. However, the separation rate contributes up to one half of the total effect on impact, as shown by the black dotted line. The largest effect on unemployment is reached earlier for the separation rate than for the job-finding rate.

- Job Flows, Employment Dynamics, and Job Reallocation. The response of employment growth is driven largely by job destruction (black dotted line in the employment growth panel of Figure 3). The responses of the job-destruction rate are similar in shape to those of the separation rate, but larger in magnitude. The responses of the job-creation rate are the mirror image of the IRFs of the job-destruction rate. Job destruction responds to shocks twice as much as job creation does. A sizable number of the 


\section{Figure 3}

\section{Price Restriction: IRFs for Labor Market Variables (percent): Demand and Supply Shocks}
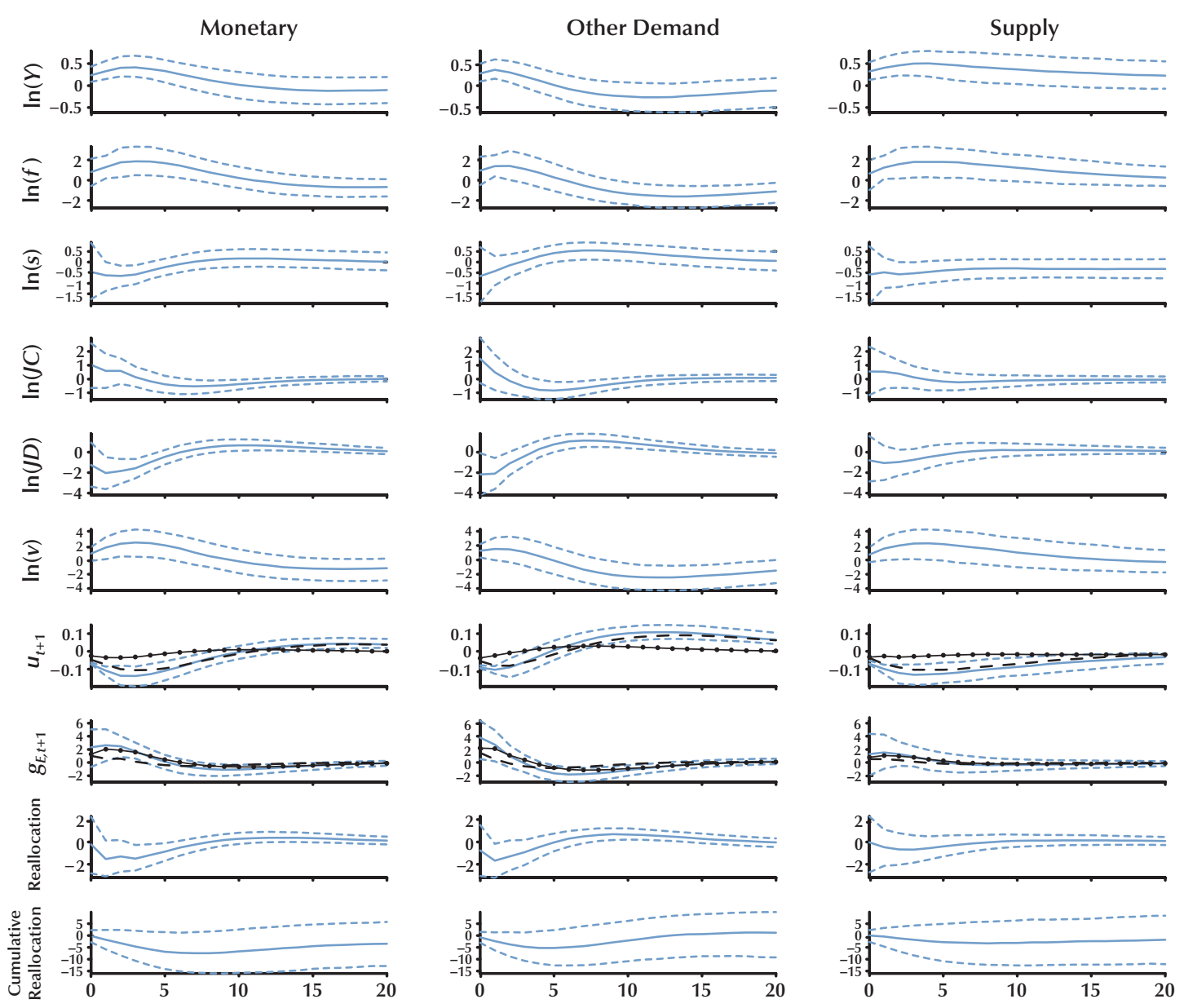

NOTE: Median (solid line), 16th and 84th percentiles (dashed lines) of posterior distributions. Black lines in the $u$-panel are the contributions of the job-finding (dashed) and the separation rates (dotted) to unemployment. Black lines in the $g_{E}$-panel are the contributions of job creation (dashed) and job destruction (dotted) to employment growth.

responses of job flows to supply shocks involve a decrease in job creation and an increase in job destruction. All shocks increase the growth rate of employment and reduce reallocation. The drop in reallocation is more pronounced for demand shocks. We do not find a significant permanent effect on cumulative reallocation.

The similarity across shocks may support the one-shock approach taken in the literature studying the business cycle properties of the
Mortensen-Pissarides model. Although the persistence of the effects differs, all shocks raise job finding, vacancies, and job creation; they lower separations and job destruction in a similar fashion. However, the difference in persistence across shocks casts doubts on a reconciliation of the Mortensen-Pissarides model with the observed labor market behavior that is specific to a particular shock. The considerable fraction of atypical responses to supply shocks suggests that a further analysis of shocks different from the one we con- 
sider is necessary (see Braun, De Bock, and DiCecio, 2006; López-Salido and Michelacci, 2007).

The hump-shaped response of the job-finding rate and vacancies to shocks is not consistent with the Mortensen-Pissarides model and with most of the literature. This finding is in line with Fujita (2004), who identifies a unique aggregate shock in a trivariate VAR including worker flows variables, scaled by employment, and vacancies. This aggregate shock is identified by restricting the responses of employment growth (nonnegative for four quarters), the separation rate (nonpositive on impact), and the hiring rate (nonnegative on impact). Our identification strategy confirms these findings without restricting worker flow variables. Where we use the job-finding probability in our VAR, Fujita (2004) includes the hiring rate to measure worker flows into employment. The hiring rate measures worker flows into employment scaled by the size of the employment pool. The job-finding rate measures the probability of exiting the unemployment pool. Although both arguably reflect movements of workers into employment (see Shimer, 2007), the difference in scaling leads to a different qualitative behavior of the two series in response to an aggregate shock. The response of the job-finding rate shows a persistent increase. Fujita's hiring rate initially increases but quickly drops below zero because of the swelling employment pool.

The mildly negative effect on cumulative reallocation is at odds with Caballero and Hammour (2005), who find that expansionary aggregate shocks have positive effects on cumulative reallocation.

For monetary policy shocks, the IRFs of aggregate variables are consistent with Christiano, Eichenbaum, and Evans (1999), who use a recursiveness restriction to identify a monetary policy shock. However, Christiano, Eichenbaum, and Evans (1999) obtain a more persistent interest rate response and inflation exhibits a price puzzle, i.e., inflation declines in response to an expansionary monetary policy shock. The latter difference is forced by our identification scheme. The job flows responses are consistent with estimates in Trigari (2009) and the worker flows and vacancies responses with those in Braun (2005).
The last row of Figure 2 shows the IRFs of labor productivity for 100 quarters. Average labor productivity, which is unrestricted, displays a persistent yet weak increase in response to supply shocks. On the other hand, productivity shows no persistent response to demand or monetary shocks. The medium-run response of labor productivity to supply shocks is consistent with a technology shocks interpretation.

Table 4 reports the median of the posterior distribution of variance decompositions, i.e., the percentage of the $j$-periods-ahead forecast error accounted for by the identified shocks. The forecast errors of output and labor productivity are driven primarily by supply shocks. Interestingly, the demand shocks have a greater impact on labor market variables than the supply shock. The greater importance of demand shocks suggests that more attention should be paid to shocks other than technology in the evaluation of the basic labor market search model.

A vast and growing literature analyzes the response of hours worked to technology shocks in VARs. Shea (1999), Galì (1999, 2004), Basu, Fernald, and Kimball (2006), and Francis and Ramey (2005) argue that hours decrease on impact in response to technology shocks. This result is at odds with the standard RBC model, which implies an increase in hours worked in response to a positive technology shock. The conclusion drawn is that the RBC model should be amended by including nominal rigidities, habit formation in consumption and investment adjustment costs, a short-run fixed proportion technology, or different shocks. ${ }^{15}$ Our results on the importance of demand shocks in driving labor market variables and on atypical responses of these variables to supply shocks can be interpreted as an extension of the negative hours response findings, though in a milder form.

The last column in Table 4 shows the variance contributions of the shocks at business cycle frequencies. The contribution of shock $i$ to the total variance is computed as follows:

\footnotetext{
${ }^{15}$ Christiano, Eichenbaum, and Vigufsson (2004), on the other hand, argue that the negative impact response of hours to technology shocks is an artifact of overdifferencing hours in VARs.
} 


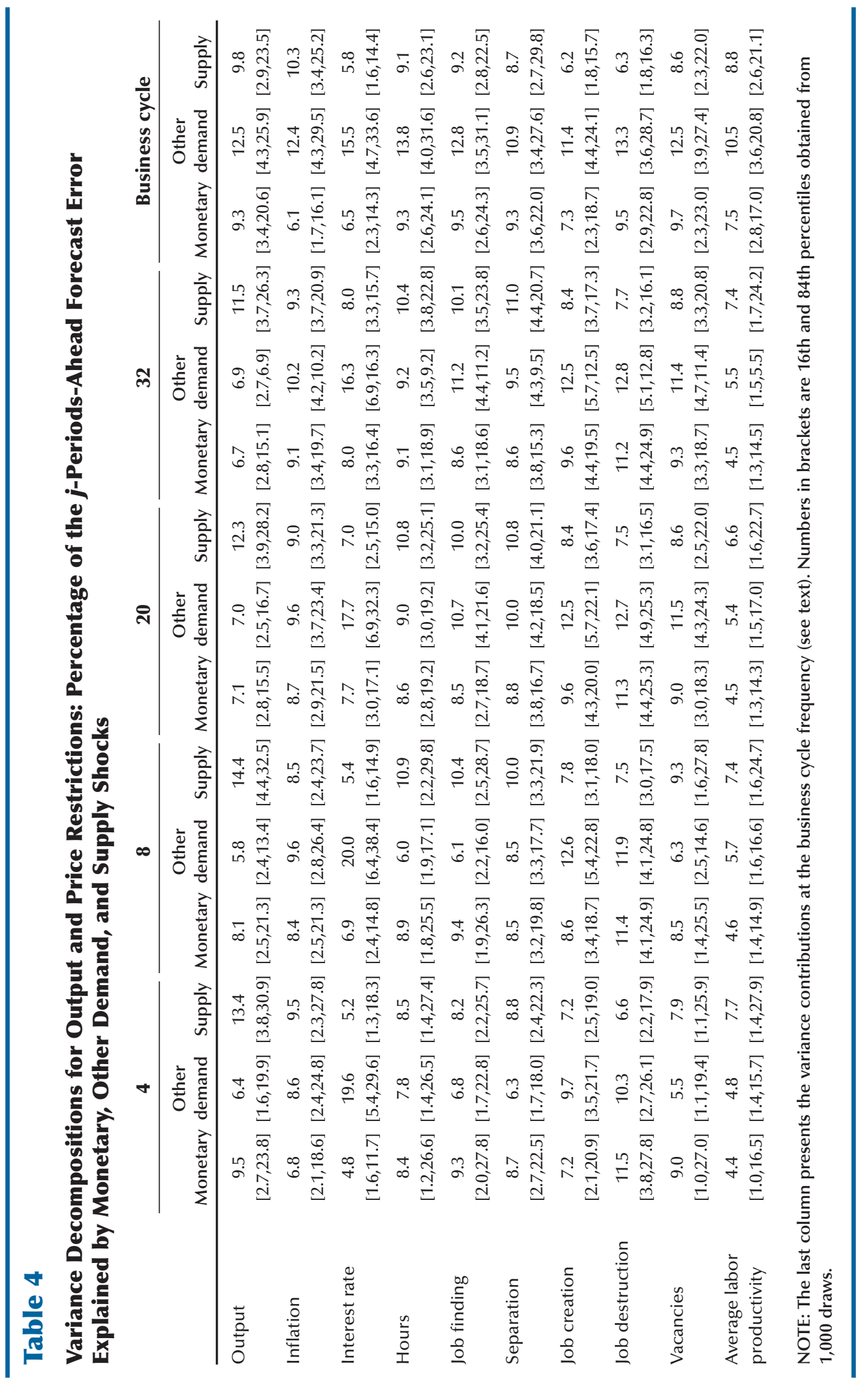




\section{Table 5}

\section{Matching Function Estimates for Output and Price Restrictions: Elasticities and Matching Efficiency}

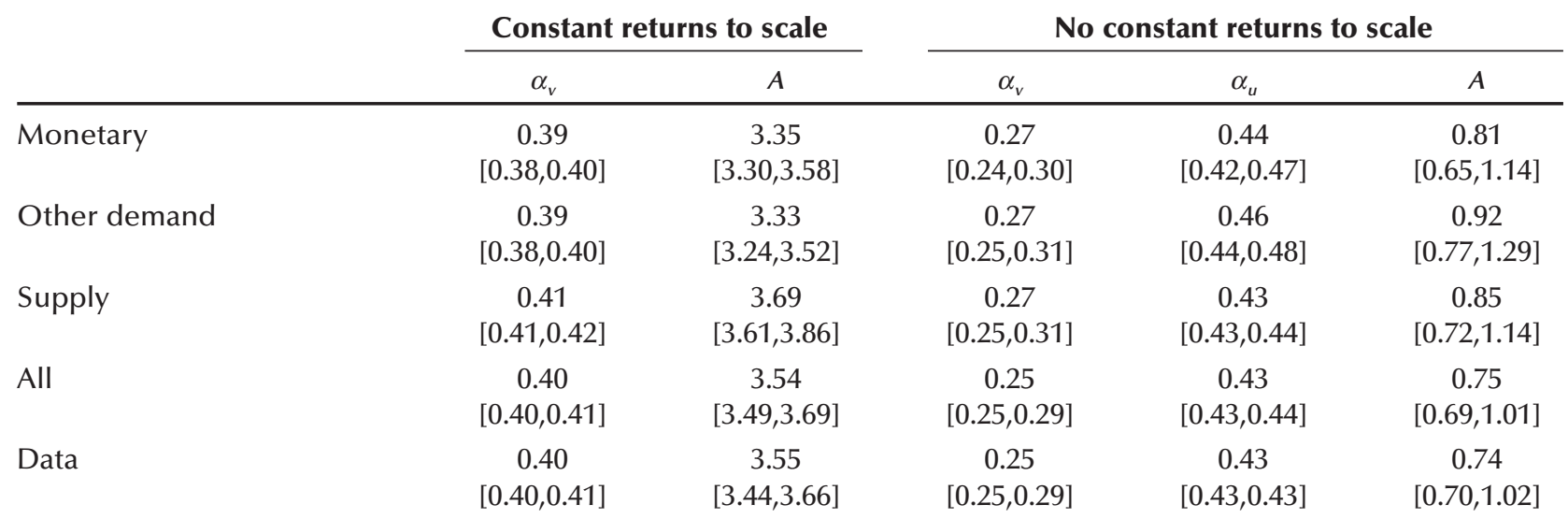

NOTE: Median of the posterior distribution; 16th and 84th percentiles are in brackets.

- We simulate data with only shock $i$, say $Z_{t}^{i}$.

- We band-pass filter $Z_{t}^{i}$ and $Z_{t}$ to obtain their business cycle components, $\left(Z_{t}^{i}\right)^{B C}$ and $\left(Z_{t}\right)^{B C}$, respectively.

- The contribution of shock $i$ is computed by dividing the variance of $\left(Z_{t}^{i}\right)^{B C}$ by the variance of $\left(Z_{t}\right)^{B C}$.

The three right panels of Table 4 show the variance contribution with the price-output restriction. The nonmonetary demand shock is the most important shock. The monetary and supply shocks contribute about equally to the business cycle variation of labor and non-labor market variables.

\section{Matching Function Estimates}

We investigate further the possibility of differential labor market responses to shocks by estimating a shock-specific matching function. In the Mortensen-Pissarides model, the number of hires $(f \times U)$ is related to the size of the unemployment pool and the number of vacancies via a matching function, $M(U, V) .{ }^{16}$ Assuming a Cobb-Douglas functional form, the matching function is given by

\footnotetext{
${ }^{16}$ Petrongolo and Pissarides (2001) survey the matching function literature.
}

$$
M(U, V)=A U^{\alpha_{u}} V^{\alpha_{v}},
$$

where $\alpha_{V}$ is the elasticity of the number of matches with respect to vacancies, $\alpha_{u}$ is the elasticity with respect to unemployment, and $A$ captures the overall efficiency of the matching process.

Under the assumption of constant returns to scale (CRS), i.e., $\alpha_{u}+\alpha_{V}=1$, the job-finding rate can then be expressed as

$$
\log \left(f_{t}\right)=\log (A)+\alpha_{V}\left(\log \left(v_{t}\right)-\log \left(u_{t}\right)\right) .
$$

If we do not impose CRS, then

$$
\log \left(f_{t}\right)=\log (A)+\alpha_{V} \log \left(v_{t}\right)-\alpha_{u} \log \left(u_{t}\right)
$$

To consider the effect of the shocks identified above on the matching process, we obtain a sample of 1,000 draws from the posterior distributions of $A$ and the elasticity parameters estimated from artificial data. Each draw involves the following steps:

- a vector of accepted residuals is constructed as if the shock(s) of interest were the only structural shock(s);

- this vector of accepted residuals and the VAR parameters are used to generate artificial data, $\widetilde{Z}_{t}$; 


\section{Table 6}

\section{Sign Restrictions: Demand and Supply Shocks}

\begin{tabular}{lccc} 
& \multicolumn{2}{c}{ Demand shocks } & \\
\cline { 2 - 3 } & Monetary & Other & Supply shocks \\
\hline Productivity & Not $\uparrow 33-80$ & Not $\uparrow 33-80$ & $\uparrow 33-80$ \\
Output & $\uparrow 1-4$ & $\uparrow 1-4$ & - \\
Price level & $\uparrow 1-4$ & $\uparrow 1-4$ & - \\
Interest rate & $\downarrow 1$ & $\uparrow 1$ & - \\
\hline
\end{tabular}

- unemployment is constructed using the steady-state approximation $\widetilde{u}_{t+1} \cong \widetilde{s}_{t} /\left(\widetilde{s}_{t}+\right.$ $\tilde{f}_{t}$ ) from the artificial data;

- $\log \left(\tilde{f}_{t}\right)$ is regressed on either $\log \left(\widetilde{v}_{t}\right)$ and $\log \left(\widetilde{u}_{t}\right)$ (not assuming CRS) or $\log \left(\widetilde{v}_{t} / \widetilde{u}_{t}\right)$ (under the CRS assumption).

The artificial data constructed using only monetary shocks, for example, induce a posterior distribution for the elasticity parameters and $A$ for a hypothetical economy in which monetary shocks are the only source of fluctuations.

Table 5 reports the median, 16th, and 84th percentiles of 1,000 draws from the posterior distributions for the price-output identification scheme. The first two columns show the estimates for $\alpha_{V}$ and $A$ when CRS are imposed. The CRS estimates suggest that aggregate shocks do not entail a differential effect on the matching process. The estimated efficiency parameters are somewhat lower for monetary and demand shocks than for the supply shock, but the median estimates differ by less than 5 percent. The last three columns of Table 5 show the unrestricted estimates for $\alpha_{v}, \alpha_{u}$, and $A$. Estimates of $\alpha_{V}$ and $\alpha_{u}$ across shocks are close and the sum of the coefficients is around 0.70 , corresponding to decreasing returns to scale. There are no significant differences in the median estimates of the efficiency parameter $A$.

\section{ROBUSTNESS}

We analyze the robustness of our results by considering medium-run and long-run restrictions on productivity to identify technology shocks.
Subsample stability and a minimal VAR specification to identify the shocks of interest are also considered.

\section{Restricting the Medium-Run Response of Labor Productivity}

Pushing the technological interpretation further, we identify supply shocks as ones that increase labor productivity in the medium run. The short-run responses of output and the price level are left unrestricted. This allows us to capture, as supply shocks, news effects on future technological improvements (see Beaudry and Portier, 2006). Also, this restriction is similar to the longrun restrictions used in the literature (see Galì, 1999). We will analyze the latter in the next subsection. The advantage of a medium-run restriction is that it allows the identification of the other shocks within the same framework as above.

In particular, a technology shock is required to raise labor productivity in the medium run, i.e., throughout quarters 33 to 80 following the shock. On the other hand, demand-side shocks are restricted to have no positive medium-run impact on labor productivity, while affecting output, the price level, and the interest rate as above (see the previous section "Price and Output Restrictions"). (The identifying restrictions are summarized in Table 6.) This restriction is similar, in spirit, to the long-run restriction on productivity adopted by Galì (1999). Uhlig (2004) and Francis, Owyang, and Roush (2008) identify technology shocks in ways similar to our mediumrun productivity restriction. According to Uhlig (2004), a technology shock is the only determinant of the $k$-periods-ahead forecast error variance. Identification in Francis, Owyang, and Roush (2008) is data driven and attributes to technology shocks the largest share of the $k$-periods-ahead forecast error variance.

Figures 4 and 5 report the median, 16th, and 84th percentiles of 1,000 draws from the posterior distribution of acceptable IRFs to the structural shocks. ${ }^{17}$ By construction, the demand-side shocks identified satisfy the restrictions in the

\footnotetext{
17 The acceptance rate is 11.7 percent.
} 


\section{Figure 4}

\section{Labor Productivity Restriction: IRFs for Non-Labor Market Variables and Hours (percent): Demand and Supply Shocks}
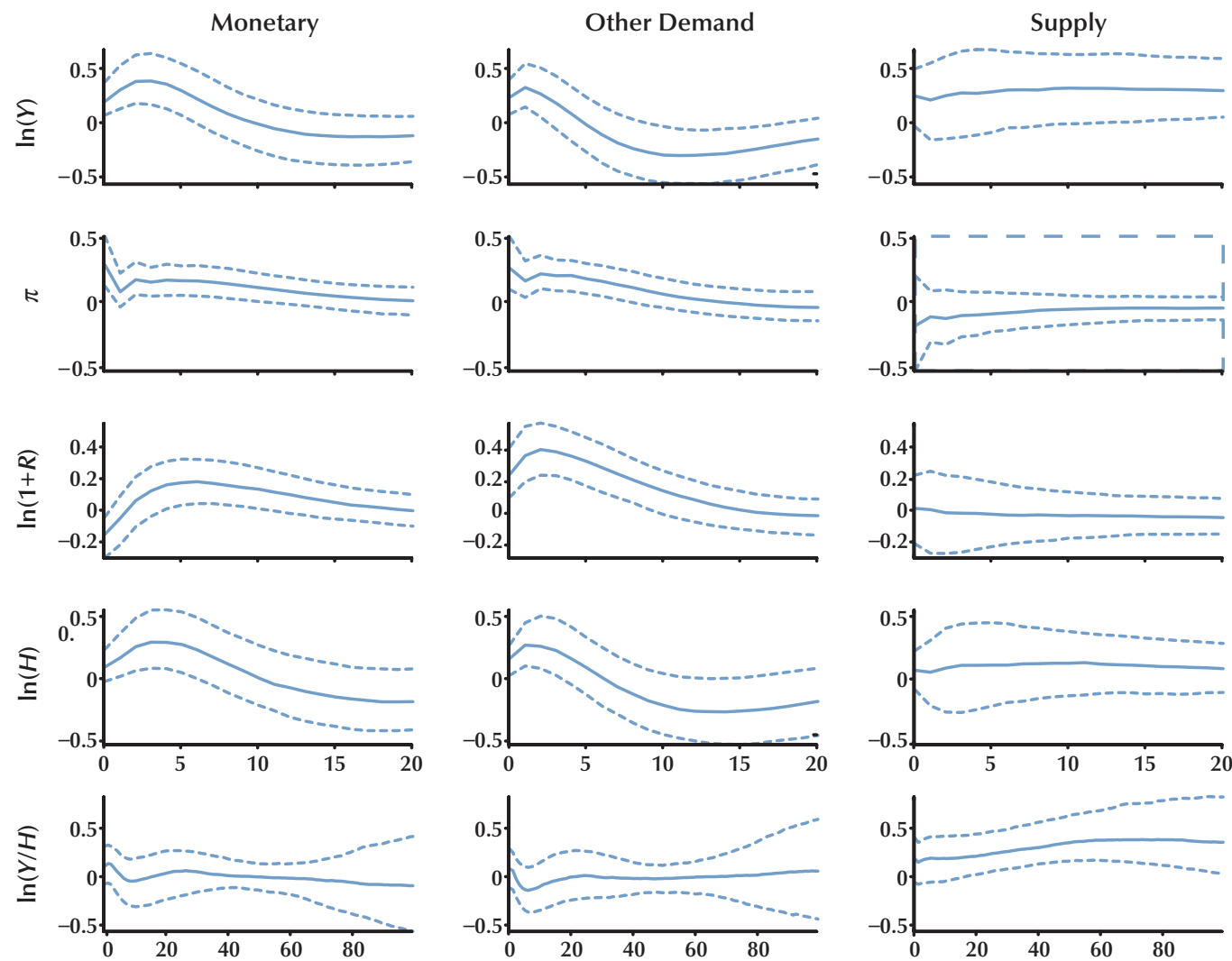

NOTE: Median (solid line), 16th and 84th percentiles (dashed lines) of posterior distributions.

previous section as well. The responses of all variables to demand-side shocks and of output and inflation to supply shocks are almost identical to the ones above. A sizable fraction (49.3 percent) of the supply shocks identified by restricting productivity in the medium run generate shortrun responses of output and prices of opposite sign. The responses of the labor market variables to the supply shocks are smaller in absolute value than under the previous identification scheme. Furthermore, a sizable fraction of the responses of labor market variables point to a reduction in employment and hours and an increase in unemployment.
For the variance decompositions displayed in Table 7, the two demand shocks are more important than the supply shock in driving fluctuations in labor market variables at different horizons. This is also true for the variance contributions at business cycle frequencies.

Table 8 shows the matching function estimates under the labor productivity identification scheme. The estimates are very similar to our benchmark analysis. Now, only the efficiency of the matching process in response to nonmonetary demand shocks is lower than the corresponding estimate for the supply shock under CRS. 


\section{Figure 5}

\section{Labor Productivity Restriction: IRFs for Labor Market Variables (percent): Demand and Supply Shocks}
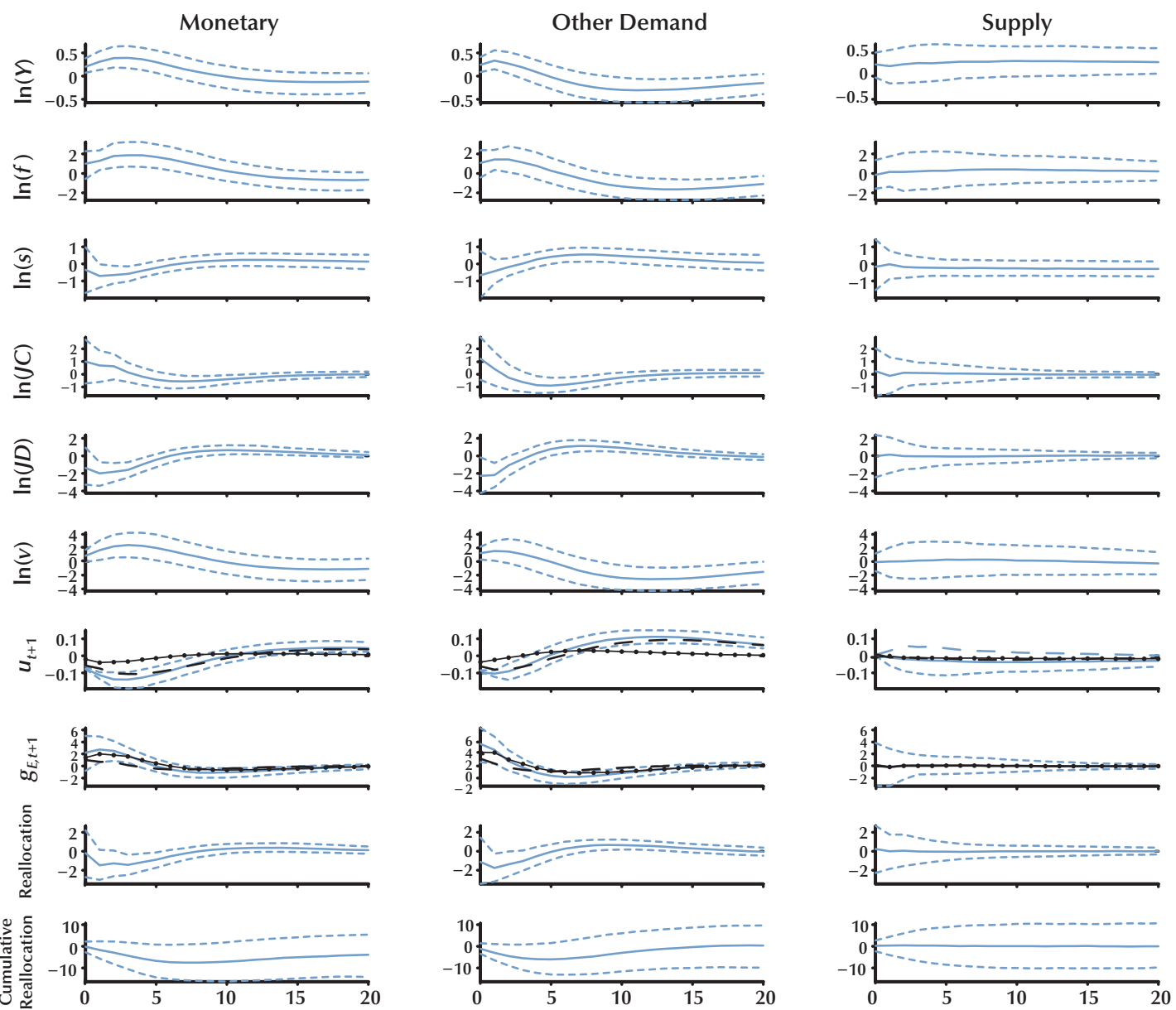

NOTE: Median (solid line), 16th and 84th percentiles (dashed lines) of posterior distributions. Black lines in the $u$-panel are the contributions of the job-finding (dashed) and the separation rates (dotted) to unemployment. Black lines in the $g_{E}$-panel are the contributions of job creation (dashed) and job destruction (dotted) to employment growth. 


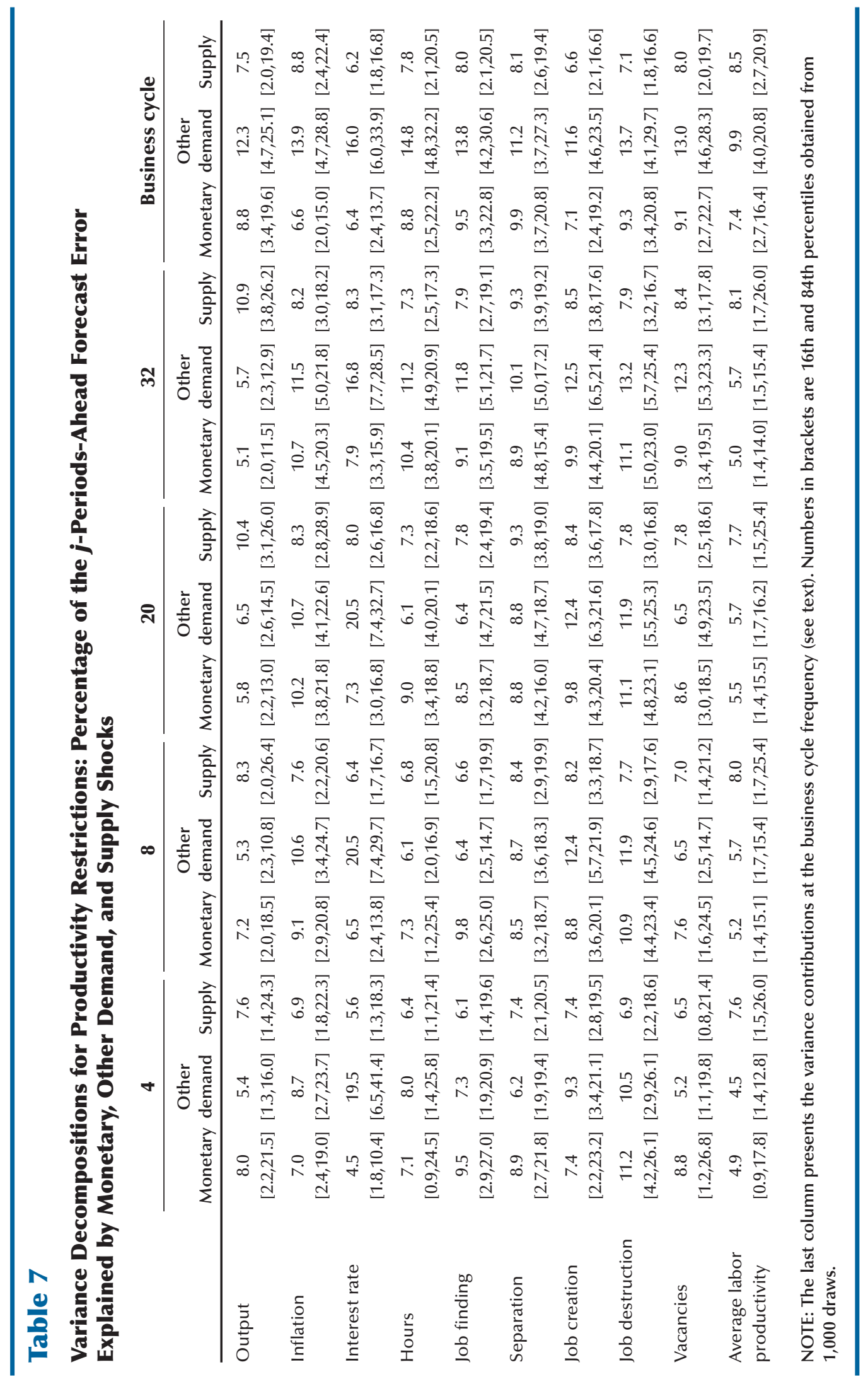


Table 8

Matching Function Estimates for Productivity Restrictions: Elasticities and Matching Efficiency

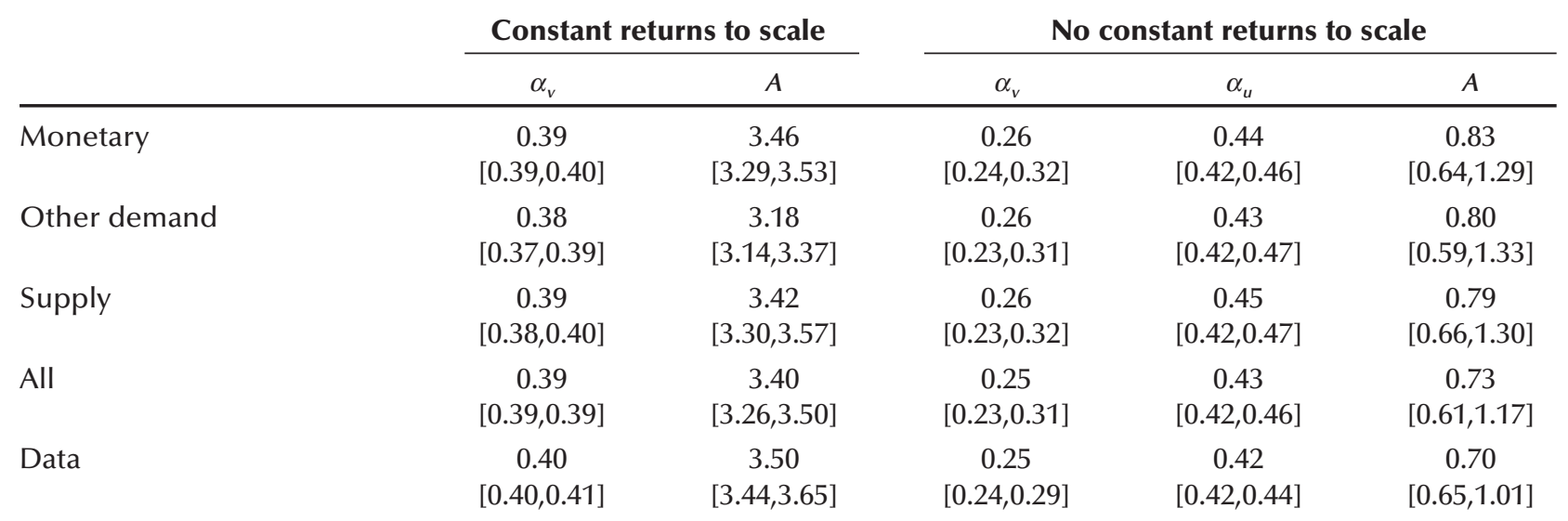

NOTE: Median of the posterior distribution; 16th and 84th percentiles in brackets.

\section{Restricting Labor Productivity Using a Long-Run Restriction}

Following Galì (1999), technology shocks are identified using long-run restrictions. Technology shocks are the only shocks to affect average labor productivity in the long run. The long-run effects of the structural shocks are given by

$$
\begin{aligned}
& Z_{\infty}=\Theta \varepsilon_{t}, \\
& \Theta \equiv[I-A(1)]^{-1}\left(A_{0}\right)^{-1} .
\end{aligned}
$$

The identifying assumption boils down to assuming that the first row of matrix $\Theta$ has the following structure:

$$
\Theta(1,:)=\left[\Theta(1,1) \quad 0_{1 \times 9}\right] .
$$

Additionally, monetary policy shocks are identified by means of a recursiveness assumption as in Christiano, Eichenbaum, and Evans (1999) by assuming that the ninth column of $A_{0}$ has the following structure ${ }^{18}$ :

$$
A_{0}(:, 9)=\left[\begin{array}{ll}
0_{1 \times 9} & A_{0}(9,9)
\end{array}\right]^{\prime} .
$$

This identification assumption can be interpreted as signifying that the monetary authority follows a Taylor-rule-like policy, which responds to all the variables ordered before the interest rate in the VAR.

Figure 6 shows the impulse responses to a technology shock. None of the responses of the labor market variables is significantly different from zero. Figure 7 shows the response to a monetary policy shock. The responses are consistent with the ones identified above.

Table 9 displays the variance decompositions at various horizons and at business cycle frequencies. Although monetary policy shocks contribute much less to the variance of output and productivity than the technology shocks, fluctuations in the labor market variables are to a much larger extent driven by the monetary shock.

\section{Subsample Stability ${ }^{19}$}

Several authors ${ }^{20}$ document a drop in the volatility of output, inflation, interest rates, and

\footnotetext{
${ }^{18}$ Notice that there is one overidentifying restriction. The first element of $\varepsilon_{\mathrm{t}}$ would be just identified by imposing the long-run restriction. The identification of monetary policy shocks imposes one additional zero restriction.

${ }^{19}$ The full set of IRFs and variance decompositions for the two subsamples is available on request.

${ }^{20}$ See Kim and Nelson (1999), McConnel and Perez-Quiros (2000), and Stock and Watson (2003).
} 


\section{Figure 6}

\section{IRFs to a Technology Shock Identified with a Long-Run Restriction on Productivity}
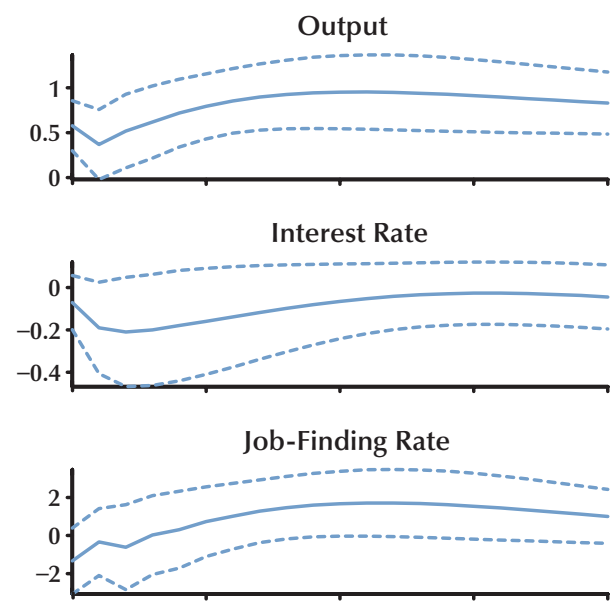

Job Creation
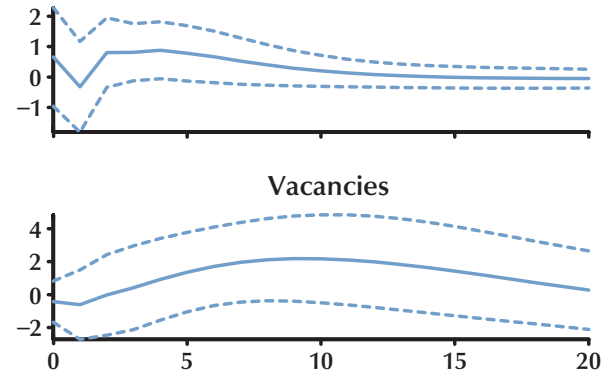

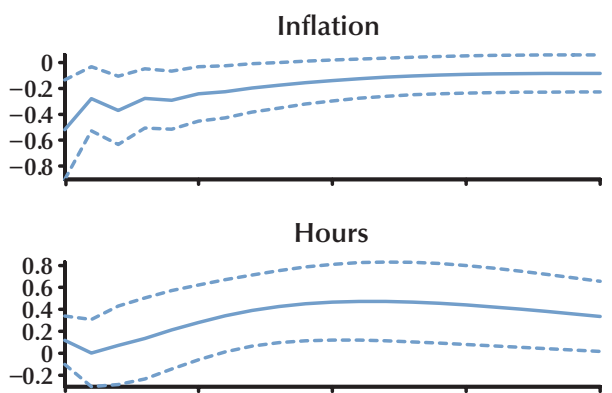

Separation Rate

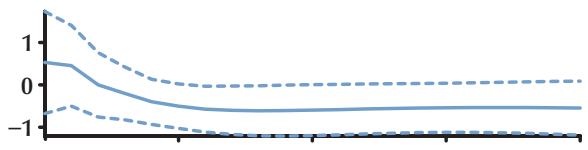

Job Destruction
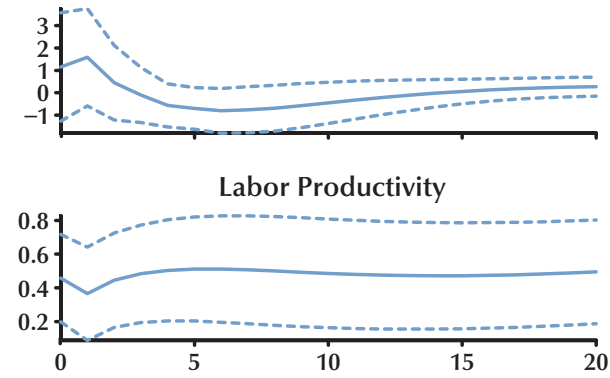

other macroeconomic variables since the earlyor mid-1980s. Motivated by these findings, we estimate our SVAR with pre-1984 and post-1984 subsamples. The post-1984 responses have similar shapes, but are smaller than the pre-1984 and the whole-sample responses for all the shocks. This is consistent with a reduction in the volatility of the structural shocks. However, supply shocks have more persistent effects in the post1984 subsample for both identification schemes. The responses of labor market variables to supply shocks identified by restricting productivity are insignificantly different from zero for both subsamples.

In terms of forecast error decomposition, supply shocks are the most important for output in the post-1984 subsamples; for hours, monetary shocks are the most important in the pre-1984 subsample, while in the post-1984 subsamples the three shocks we identify are equally important. ${ }^{21}$ For worker and job flows, each demand shock is at least as important as the supply shock, across subsamples and identification schemes.

\section{Small VAR}

To further check the robustness of our results, we used a lower-dimensional VAR containing labor productivity, inflation, the nominal interest rate, and hours. Shocks are identified using the same sign restrictions as in the section "Price and Output Restrictions." For a draw that satisfies

${ }^{21}$ Our results on the increased importance in the later subsamples of supply shocks in accounting for the forecast error of output are consistent with Fisher (2006). On the other hand, for hours, Fisher (2006) argues that the importance of technology shocks decreased after 1982. 


\section{Figure 7}

\section{IRFs to a Monetary Shock Identified with a Contemporaneous Restriction}
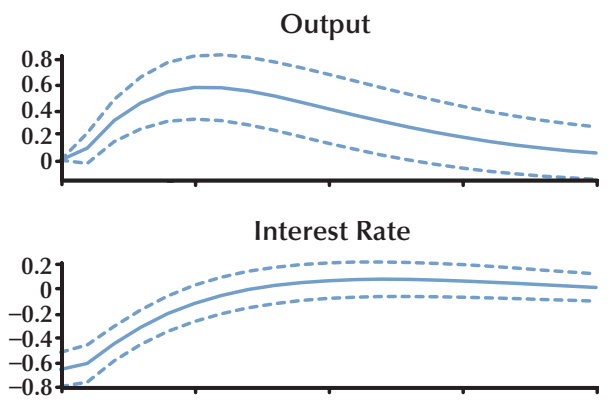

Job-Finding Rate

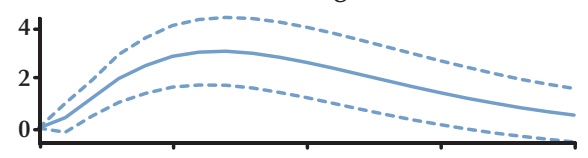

Job Creation

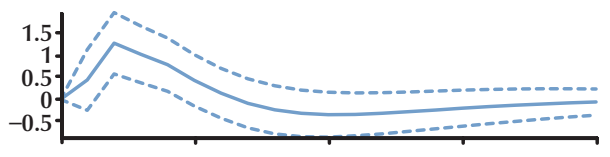

Vacancies

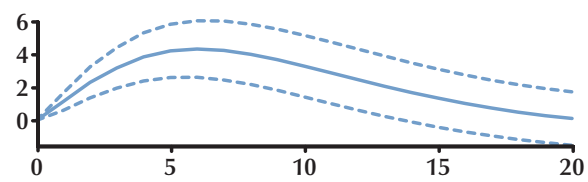

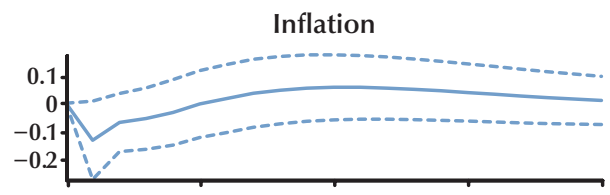

Hours

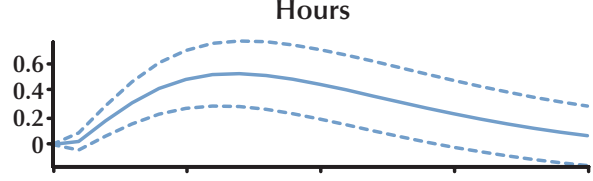

Separation Rate

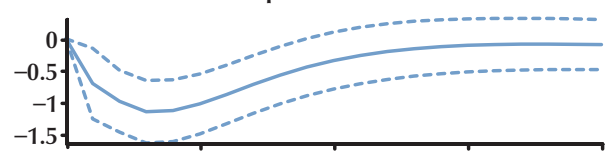

Job Destruction

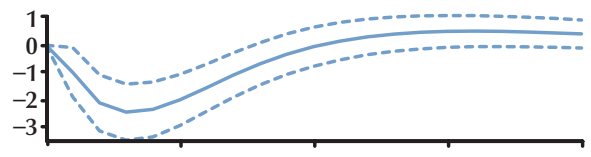

Labor Productivity

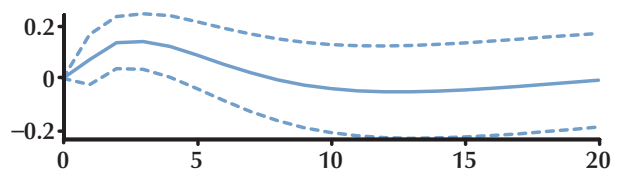

the identifying restrictions we run the following regression:

$$
\begin{aligned}
& z_{t}=\alpha+\sum_{j=0}^{T} \beta_{j}^{M} \hat{\varepsilon}_{t-j}^{M}+\sum_{j=0}^{T} \beta_{j}^{D} \hat{\varepsilon}_{t-j}^{D} \\
& +\sum_{j=0}^{T} \beta_{j}^{S} \hat{\varepsilon}_{t-j}^{S}+V_{z, t},
\end{aligned}
$$

where $\hat{\varepsilon}^{M}, \hat{\varepsilon}^{D}$, and $\hat{\varepsilon}^{S}$ denote the three shocks identified in the minimal VAR and $z_{t}$ is one of the variables not contained in the VAR, i.e., vacancies, the job-finding rate, the separation rate, the jobcreation rate, or the job-destruction rate. Also, $\alpha$ and $v_{z, t}$ denote a constant and an i.i.d. error term, respectively. The length of the moving average terms was set to $T=30$. The impulse responses for the labor market variables are given by the respective $\beta_{j}^{i}$.

The conclusions are qualitatively similar to the ones reached above. However, the responses of the job-finding rate and vacancies to a nonmonetary demand shock are less persistent than in our benchmark analysis. Furthermore, the responses to supply shocks are even less pronounced than for the larger VAR specification discussed previously. ${ }^{22}$ Again, demand shocks are as important as supply shocks in driving fluctuations of the labor market variables.

\section{CONCLUSION}

This paper considers alternative short-run, medium-run, and long-run restrictions to identify structural shocks in order to analyze their impact on worker flows, job flows, vacancies, and hours.

\footnotetext{
22 The figures are available on request.
} 


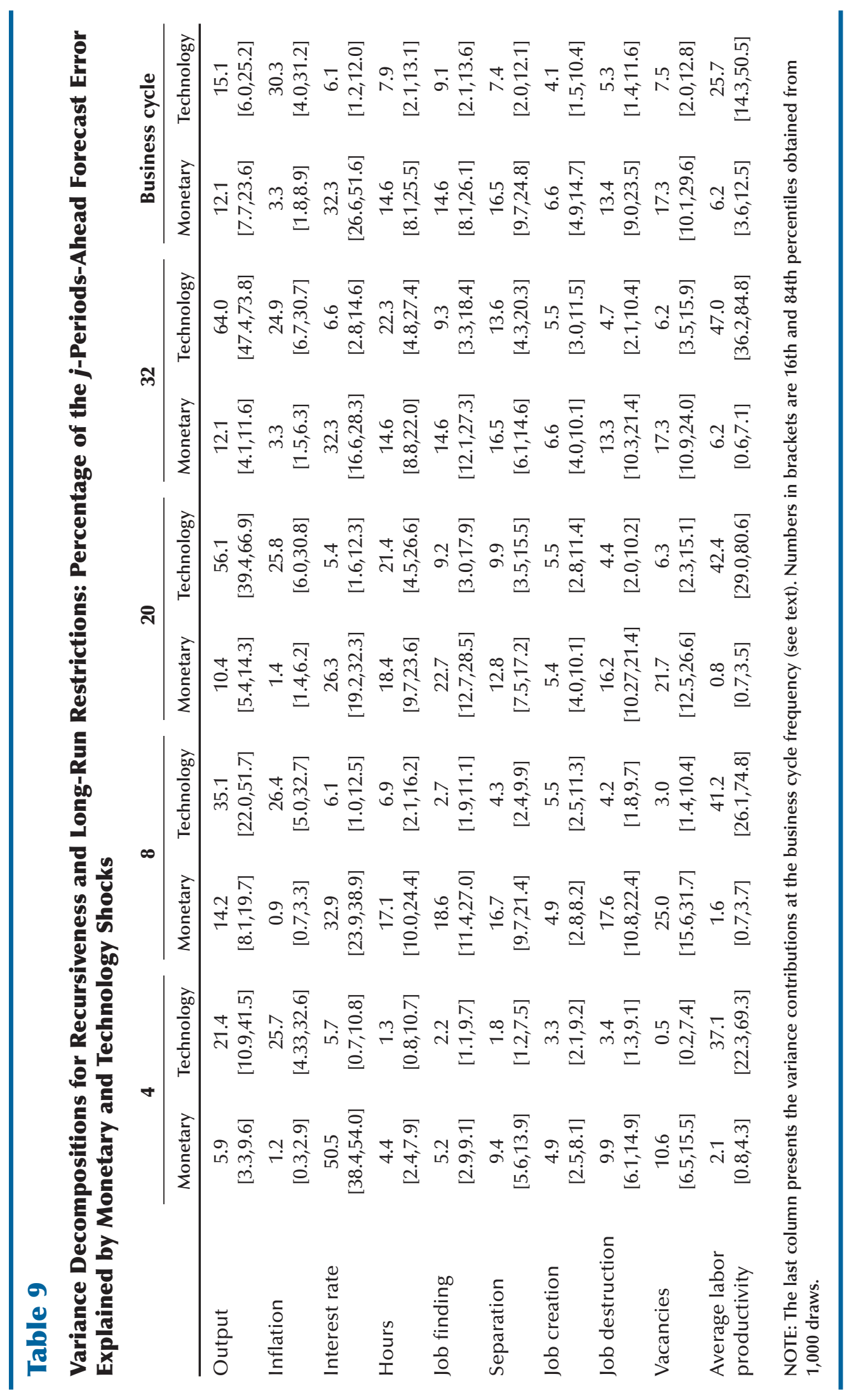




\section{Braun, De Bock, DiCecio}

We find that demand shocks are more important than supply shocks (technology shocks, more specifically) in driving labor market fluctuations. When identified by means of short-run price and output restrictions, supply shocks have effects that are qualitatively similar to those of demand shocks: Both demand and supply shocks raise employment, vacancies, the job-creation rate, and the job-finding rate while lowering unemployment, separations, and job destruction. These effects are more persistent for supply shocks. When identified by means of medium-run or longrun restrictions on labor productivity, supply shocks do not have a clear effect on the labor market variables.

\section{REFERENCES}

Andolfatto, David. "Business Cycles and Labor-Market Search." American Economic Review, 1996, 86(1), pp. 112-32.

Basu, Susanto; Fernald, John G. and Kimball, Miles S. "Stock Prices, News and Economic Fluctuations." NBER Working Paper No. 10548, National Bureau of Economic Research, 2004.

Basu, Susanto; Fernald, John G. and Kimball, Miles S. "Are Technology Improvements Contractionary?" American Economic Review, 2006, 96(5), pp. 1418-48.

Beaudry, Paul and Portier, Franck. "Stock Prices, News and Economic Fluctuations." American Economic Review, 2006, 96(4), pp. 1293-307.

Blanchard, Olivier J. and Diamond, Peter. "The Cyclical Behavior of the Gross Flows of U.S. Workers." Brookings Papers on Economic Activity, 1990, 21(2), pp. 85-143.

Braun, Helge. "(Un)Employment Dynamics: The Case of Monetary Policy Shocks." Unpublished manuscript, University of British Columbia, 2005.

Braun, Helge; De Bock, Reinout and DiCecio, Riccardo. "Aggregate Shocks and Labor Market Fluctuations." Working Paper No. 2006-004A, Federal Reserve Bank of St. Louis, 2006.
Caballero, Ricardo J. and Hammour, Mohammad L. "The Cost of Recessions Revisited: A ReverseLiquidationist View." Review of Economic Studies, 2005, 72(2), pp. 313-41.

Christiano, Lawrence J.; Eichenbaum, Martin and Evans, Charles L. "Monetary Policy Shocks: What Have We Learned and to What End?" in John B. Taylor and Michael Woodford, eds., Handbook of Macroeconomics, Vol. 1A, Chap. 1. New York: Elsevier, 1999, pp. 65-148.

Christiano, Lawrence J.; Eichenbaum, Martin and Vigfusson, Robert. "The Response of Hours to a Technology Shock: Evidence Based on Direct Measures of Technology." Journal of the European Economic Association, 2004, 2(2-3), pp. 381-95.

Christiano, Lawrence J. and Fitzgerald, Terry J. "The Band Pass Filter.” International Economic Review, 2003, 44(2), pp. 435-65.

Davis, Steven J.; Faberman, R. Jason and Haltiwanger, John C. "The Flow Approach to Labor Markets: New Data Sources, Micro-Macro Links and the Recent Downturn." Journal of Economic Perspectives, 2006, 20(3), pp. 3-26.

Davis, Steven J. and Haltiwanger, John C. "Gross Job Creation, Gross Job Destruction, and Employment Reallocation." Quarterly Journal of Economics, 1992, 107(3), pp. 819-63.

Davis, Steven J. and Haltiwanger, John C. "On the Driving Forces behind Cyclical Movements in Employment and Job Reallocation." American Economic Review, 1999, 89(5), pp. 1234-58.

Davis, Steven J.; Haltiwanger, John C. and Schuh, Scott. Job Creation and Destruction. Boston: MIT Press, 1996.

Faberman, R. Jason. "Gross Job Flows over the Past Two Business Cycles: Not All 'Recoveries' Are Created Equal.” Discussion Paper No. 372, U.S. Bureau of Labor Statistics, 2004.

Fisher, Jonas D.M. "The Dynamic Effects of Neutral and Investment-Specific Technology Shocks." Journal of Political Economy, 2006, 114(3), pp. 413-51. 
Francis, Neville; Owyang, Michael T. and Roush, Jennifer E. "A Flexible Finite-Horizon Identification of Technology Shocks.” Working Paper No. 2005024E, Federal Reserve Bank of St. Louis, 2008.

Francis, Neville and Ramey, Valerie A. "Is the Technology-Driven Real Business Cycle Hypothesis Dead? Shocks and Aggregate Fluctuations Revisited." Journal of Monetary Economics, 2005, 52(8), pp. 1379-99.

Fujita, Shigeru. "Vacancy Persistence.” Working Paper No. 04-23, Federal Reserve Bank of Philadelphia, 2004.

Galì, Jordi. "Technology, Employment, and the Business Cycle: Do Technology Shocks Explain Aggregate Fluctuations?" American Economic Review, 1999, 89(1), pp. 249-71.

Galì, Jordi. "On the Role of Technology Shocks as a Source of Business Cycles: Some New Evidence." Journal of the European Economic Association, 2004, 2(2-3), pp. 372-80.

Hagedorn, Marcus and Manovskii, Iurii. "The Cyclical Behavior of Equilibrium Unemployment and Vacancies Revisited.” American Economic Review, 2008, 98(4), pp. 1692-706.

Hall, Robert E. "Job Loss, Job Finding, and Unemployment in the U.S. Economy over the Past Fifty Years," in Mark Gertler and Kenneth Rogoff, eds., NBER Macroeconomics Annual 2005, Vol. 20. Boston: MIT Press, 2006.

Jeffreys, Harold. Theory of Probability, Third Edition. London: Oxford University Press, 1961.

Kim, Chang-Jin and Nelson, Charles R. "Has The U.S. Economy Become More Stable? A Bayesian Approach Based on a Markov-Switching Model of the Business Cycle." Review of Economics and Statistics, 1999, 81(4), pp. 608-16.

López-Salido, David J. and Michelacci, Claudio. “Technology Shocks and Job Flows." Review of Economic Studies, 2007, 74(4), pp. 1195-227.

McConnell, Margaret M. and Perez-Quiros, Gabriel. "Output Fluctuations in the United States: What
Has Changed Since the Early 1980's?" American Economic Review, 2000, 90(5), pp. 1464-76.

Mortensen, Dale T. and Nagypál, Éva. "More on Unemployment and Vacancy Fluctuations.” NBER Working Paper No. 11692, National Bureau of Economic Research, 2005.

Mortensen, Dale T. and Pissarides, Christopher A. "Job Creation and Job Destruction in the Theory of Unemployment." Review of Economic Studies, 1994, 61(3), pp. 397-415.

Peersman, Gert. "What Caused the Early Millennium Slowdown? Evidence Based on Vector Autoregressions." Journal of Applied Econometrics, 2005, 20(2), pp. 185-207.

Petrongolo, Barbara and Pissarides, Christopher A. "Looking into the Black Box: A Survey of the Matching Function." Journal of Economic Literature, 2001, 39(2), pp. 390-431.

Shea, John. "What Do Technology Shocks Do?” in Ben S. Bernanke and Julio J. Rotemberg, eds., NBER Macroeconomics Annual 1998, Vol. 13. Boston: MIT Press, 1999.

Shimer, Robert. "The Consequences of Rigid Wages in Search Models." Journal of the European Economic Association, 2004, 2(2-3), pp. 469-79.

Shimer, Robert. "The Cyclicality of Hires, Separations, and Job-to-Job Transitions." Federal Reserve Bank of St. Louis Review, 2005, 87(4), pp. 493-508.

Shimer, Robert. "Reassessing the Ins and Outs of Unemployment." Unpublished manuscript, University of Chicago, 2007.

Silva, José I. and Toledo, Manuel. "Labor Turnover Costs and the Cyclical Behavior of Vacancies and Unemployment.” Meeting Paper No. 775, Society for Economic Dynamics, 2005.

Stock, James H. and Watson, Mark W. "Has the Business Cycle Changed and Why?" in Mark Gertler, and Kenneth Rogoff, eds, NBER Macroeconomics Annual 2002, Vol. 17. Boston: MIT Press, 2003. 


\section{Braun, De Bock, DiCecio}

Trigari, Antonella. "Equilibrium Unemployment, Job Flows and Inflation Dynamics." Journal of Money, Credit, and Banking, 2009, 41(1), pp. 1-33.

Uhlig, Harald. "Do Technology Shocks Lead to a Fall in Total Hours Worked?" Journal of the European Economic Association, 2004, 2(2-3), pp. 361-71.
Uhlig, Harald. "What Are the Effects of Monetary Policy on Output? Results from an Agnostic Identification Procedure." Journal of Monetary Economics, 2005, 52(2), pp. 381-419.

\section{APPENDIX}

Table A1 describes the data (other than the job flows and worker flows data) used in the paper and provides the corresponding Haver mnemonics. The data are readily available from other commercial and noncommercial databases, as well as from the original sources (Bureau of Economic Analysis, Bureau of Labor Statistics, Board of Governors of the Federal Reserve System).

\section{Table A1}

\section{Other Data}

Variable

Civilian noninstitutional population

Output per hour of all persons (nonfarm business sector)

Output (nonfarm business sector)

GDP: chain price index

Real GDP

Federal funds (effective) rate

Hours of all persons (nonfarm business sector)

Index of help-wanted advertising in newspapers

Civilian labor force (16 years and older)

Civilian unemployment rate (16 years and older)
Units

Thousands, NSA

Index, 1992=100, SA

Index, 1992=100, SA

Index, 2000=100, SA

Billions chained 2000 \$, SAAR

Percent p.a.

Index, 1992=100, SA

Index, 1987=100, SA

Thousands, SA

Percent, SA
Haver (USECON)

LN16N

LXNFA

LXNFO

JGDP

GDPH

FFED

LXNFH

LHELP

LF

LR

The remaining variables used in the VAR analysis are constructed from the raw data as follows:

$$
\Delta \log \left(p_{t}\right)=4 \Delta \log \left(\mathrm{JGDP}_{t}\right), H_{t}=\frac{\mathrm{LXNFH}_{t}}{\mathrm{LN16N}_{t}}, v_{t}=\frac{\mathrm{LHELP}_{t}}{\mathrm{LF}_{t}} .
$$

